\title{
What is the Role of Legal Systems in Financial Intermediation? Theory and Evidence
}

\author{
Laura Bottazzi* \\ Bologna University and IGIER
}

\author{
Marco Da Rin \\ CentER - Tilburg University, ECGI, and IGIER
}

\author{
Thomas Hellmann \\ University of British Columbia
}

February 2007

\begin{abstract}
We develop a theory and empirical test of how the legal system affects the relationship between a venture investor and an entrepreneur. The theory uses a double moral hazard framework to show how optimal contracts and investor actions depend on the quality of the legal system. The empirical evidence is based on a sample of European venture capital deals. The main results are that with better legal protection, investors give more non-contractible support and demand more downside protection, and they develop more value-adding skills. These predictions are stongly supported by the empirical analysis. We also find that the investor's legal system is more important that of the company in determining these effects, and that legal system effects persist within civil law countries.
\end{abstract}

le

${ }^{*}$ We are grateful to all the venture capital firms which provided us with data. We received valuable comments from Reneé Adams, Giacinta Cestone, Vicente Cuñat, Steve Kaplan, Michele Pellizzari, Alessandro Sembenelli, Oren Sussman, and from seminar participants at the 2005 AFA Meetings in Philadelphia, CSEF (Salerno), IDEI (Toulouse), Lugano, Pompeu Fabra, Tilburg, UBC (Vancouver), at the ECGI Corporate Governance Conference (Oxford, 2005), at the CEPRBank of Italy Conference on Effective Financial Systems (Rome, 2005), and at the Second RICAFE Conference (Frankfurt, 2004). We thank Roberto Bonfatti, Matteo Ercole, and Francesca Revelli for long hours of dedicated research assistance. Our colleague Pietro Terna made the online data collection possible. Financial support from the European Investment Fund, Bocconi University Ricerca di Base 2004, Italian Ministry of Research (FIRB grant RBAU013CNJ) and the European Commission (grant HPSE-CT-2002-00140) is gratefully acknowledged. All errors remain our own. 


\section{Introduction}

The work of La Porta et al. $(1997,1998,2000)$ demonstrates the importance of the legal system for economic activity. Their work, and a large ensuing literature shows that countries with different legal origins also systematically differ in terms of their financial systems. In this paper we ask how financial intermediation is affected by the nature of the legal system. A large theoretical literature has pointed to the importance of both contractual and non-contractual aspects of financial intermediation when an entrepreneur seeks funds for an investment project (Holmström and Tirole (1997), Hart (2001)). We then look at how the entire relationship - contractual and non-contractual - between an investor and an entrepreneur depends on the legal system.

Since it is not immediately obvious how the legal system should affect this relationship, we let our analysis be guided by theory. We examine how optimal contracts, and the resulting investor behavior, depend on the legal system. We propose a simple theory that makes three predictions. First, the better the legal system the more investors provide valueadding support. Second, the better the legal system the more they demand contractual downside protection in bad states of the world, using securities such as debt, convertible debt, or preferred equity. The underlying intuition is that investing in support activities is only worthwhile if the legal system provides investors with sufficient guarantees that these efforts will not be wasted. We also show that in a better legal system it is optimal to give the entrepreneur stronger upside incentives. As a consequence it becomes necessary to give investors additional cash flow rights on the downside, in order to satisfy their participation constraint.

Our theory also considers how the legal systems might affect financial intermediaries themselves. We consider the influence of the legal system on intermediaries' incentives to develop the competencies necessary to provide value added services. Our third prediction is that intermediaries from countries with a better legal system will provide more value added services, even when investing abroad.

To test the predictions of the theory, we use a hand-collected dataset on European venture capital investments for the period 1998-2001. We focus on venture capital as a specialized form of financial intermediation because prior research has already established the richness of relationships between venture investors and their companies. Venture capital firms can play a value-adding role in the companies they finance, both through contracting and by providing non-contractible inputs such as advice, support, and governance (Bottazzi, Da Rin and Hellmann (2006, 2007), Gompers (1995), Hellmann and Puri (2000, 2002), Hochberg (2003), Kaplan and Strömberg (2003), Lerner (1994), Lindsey (2003), Sahlman (1990), Sorensen (2006)). While this evidence mostly concerns the US, over the 
last decade venture capital has become a global phenomenon (Megginson (2004)), with Europe becoming a particularly important market (Bottazzi and Da Rin (2004), Da Rin, Nicodano, and Sembenelli (2006)). As the venture capital industry develops, there is considerable debate about whether differences in investment methods are related to differences in legal systems. Europe is therefore an excellent place to examine the effects of differences across legal systems, since European countries are fairly comparable in their stages of economic growth, yet there is a rich variety of legal systems within Europe.

Our sample consists of 1,431 venture deals from 124 venture capital firms in 17 European countries. Our primary data source is a comprehensive survey of all venture capital firms in these countries. We then augmented the data with numerous secondary sources, including commercial databases and websites. This data collection effort required considerable time and effort but allowed us to gather a dataset that has several unique advantages. The dataset is considerably larger than other hand-collected datasets on venture capital, and is much richer than the commercially available databases. It contains several measures of the interactions between venture capitalists and entrepreneurs, which allows us to assess both the contractual and the non-contractual aspects of their relationship. These measures cannot be obtained from standard sources of venture capital data (such as VenturExpert), nor from venture capital contracts. Another notable feature of the dataset is that it provides us with investments which cross over to different legal systems, involving investors from both better and worse legal systems. Both these empirical features are new to the literature.

We find strong empirical support for our theoretical predictions. Better legal systems are associated with more investor involvement and more downside protection for the investors. The results hold for legal origin, using the standard interpretation that the AngloSaxon common law system is better for investors than systems based on civil law. They also hold for two widely used index measures of the quality of the legal system: the rule of law and the degree of legal procedural complexity.

Our data also allows us to examine whether the effects of legal systems come through the company or the investor. This issue had not yet been fully explored by the literature. We provide a novel approach which enables us to establish the greater importance of the investor's legal system effects. Consistent with our model, investors from countries with stronger legal protection provide more support and demand more downside protection. This supports our theoretical prediction that the legal system affects financial outcomes not only directly, but also indirectly by affecting the extent to which financial intermediaries develop competencies.

Much of the literature uses differences between common and civil law countries to identify the effect of the legal system. Our data allows us to go one step further, and 
perform some additional, more detailed, tests by focusing on differences within civil law countries. We find that our results continue to hold in the subsample of civil law companies and investors, thus providing a stronger case for the importance of legal systems.

Our results provide new insights into how legal systems affect financial intermediation. In particular, they point to the importance of considering the relationship between investor and entrepreneur in its entirety, accounting for the interdependence between contractual and non-contractual aspects. Moreover, the analysis shows how the legal system works its effects beyond contracts and investors' actions, coming to affects investor competencies themselves. The findings have important implications for our understanding of cross country differences in financial intermediation. We discuss these implications, and their relevance for policy, in the main body of the paper.

The paper is organized as follows. Section 2 addresses the relationship with the literature. Section 3 develops the theoretical model. Section 4 describes the data. Section 5 discusses the empirical results, and Section 6 provides some further discussion. It is followed by the conclusion.

\section{Related Literature}

A few theoretical papers have begun to explore the relationship between legal systems and corporate finance choices. Shleifer and Wolfenzon (2002) examine a model where an entrepreneur wants to divert funds for private use. They show how the strength of the legal system affects the willingness to go public, and thus the equilibrium size of the capital market. Burkhart, Panunzi and Shleifer (2003) consider how the legal system affects a manager's ability to divert funds. They show that the willingness of an owner to delegate control to a manager and to sell shares to outsiders depends on the quality of the legal system. In a related vein, Burkhart and Panunzi (2004) consider the effect of shareholder protection on managerial incentives, monitoring and ownership concentration. Bergman and Nicolaievski (2004) develop a model where the quality of the judicial systems drives the quality of enforcement. We are not aware of any theory paper that specifically addresses the role of the legal system for the non-contractual aspects of financial intermediation.

Our theory examines the relative use of debt and equity as a function of the quality of legal systems. It seems natural to relate this to the literature on cost state verification (Gale and Hellwig (1985)), which has argued that debt is an optimal instrument when the cost of verifying (and thus enforcing) state-contingent returns is high. This line of argument would suggest that debt is more important in poorer legal systems. However, upon closer inspection, this line of argument does not really apply to the context of venture capital, which is fundamentally about equity investments. We are looking at a context where the 
legal system is sufficiently advanced to allow for state-contingent returns and thus the use of equity. Put differently, the question we are asking here is not whether equity investors want to switch to debt, but whether equity investors want to add some debt. One of the interesting insights that we obtain from the model is an explanation why this incremental use of debt might actually be associated with better legal systems.

Because the theoretical literature remains under-developed, much of the empirical literature has focused on documenting empirical regularities. Demirgüç-Kunt and Maksimovic (1998), examine the effects of legal systems on financial or economic outcomes, providing evidence on the link between legal origin, financial institutions and company growth. Qian and Strahan (2005) look at how legal origin affects the design of bank loan contracts. Himmelberg, Hubbard and Love (2002) examine the effect of investor protection on firms' cost of capital. Desai, Gompers and Lerner (2005) examine the relationship between legal systems and firm dynamics, including entry and exit rates.

Of particular relevance here are two recent papers based on venture capital data. Lerner and Schoar (2005) (LS henceforth) collect a sample of 210 transactions in 26 countries, made by 28 private equity firms, mostly between 1996 and 2001. They focus not purely on venture capital deals, but on private equity deals more broadly defined. Their data are mainly from developing, rather than developed countries, and their analysis is mainly based on comparing common and civil law countries (as well as former socialist systems). Among other things, they find that in countries with better legal systems, private equity investors switch from using simple securities, notably straight equity and debt, to using more sophisticated securities, such as convertible preferred stock.

Kaplan, Martel, and Strömberg (2003) (KMS henceforth) collect a sample of 145 venture deals made by 70 venture capital firms in 107 companies in 23 non-US (largely European) countries, mostly between 1998 and 2001. They compare these non-US investments with the US sample analyzed by Kaplan and Strömberg (2003). Their main dependent variables focus on contractual sophistication. Among other things, they find a positive relationship between better legal systems and the use of convertible securities. Their central finding, however, is that the coefficients for legal systems become insignificant after controlling for investors' sophistication. They measure sophistication by whether the investor is US-based or has experience investing in the US venture capital market.

Our study advances the literature on several counts. First, we develop a theoretical model that gives us a coherent framework for explaining how the legal system affects the entire financing relationship, in terms of contracts, non-contractual actions and even investor competencies. Second, we are able to empirically examine the non-contractual dimension of the venture capital relationship. This component of value-adding support has been central in much of the theoretical venture capital literature, but has not yet been 
studied empirically. Third, an interesting difference is that the prior literature identifies legal system effects mainly by comparing the US (and the UK to a limited extent) with a number of civil law countries, whereas our sample consists entirely of European investors and companies. The US is undoubtedly the leading venture capital market, implying that legal system effects could be confounded with US-specific effects, especially due to leaderfollower market dynamics. In our analysis we are also able to examine the effects of legal systems in the subsample of civil law countries only. Fourth, our analysis provides a novel approach for comparing the relative importance of the companies' versus investors' legal system. The prior literature focuses mostly on companies' legal systems and finds mixed result. ${ }^{1}$ Our analysis suggests that company legal system effects are not as robust as investor legal system effects. This is an important and novel finding that also suggests new directions for future research.

Fifth, we use a new data approach. KMS and LS gather private equity and venture capital contracts. This has the advantage of providing very detailed data on the contractual relationship between the venture capitalist and the entrepreneur. We choose a complementary approach of gathering survey data on venture capital activity. This has the advantage that we can go beyond the purely contractual aspects of the investment relationship. It also allows us to build a substantially larger sample than LS and KMS.

There are many similarities between our results and those of LS and KMS. For example, all three papers find that the use of convertible preferred securities is associated with better legal systems. However the are also some differences.

In LS company legal effects remain significant throughout, whereas in this paper their significance vanishes once we control for the investor's country. Note that one of the advantages of having a much larger sample size is that it allows us to estimate models with country fixed effects. Another difference between this paper and LS concerns the relationship between legal systems and the use of pure debt. LS find a negative relationship, whereas we find a positive relationship. The most likely explanation is sample differences, in particular the kind of investments found in the relatively poorer legal systems. In LS, those investments are largely made by non-venture private equity investors, who invest in traditional sectors such as manufacturing, and who provide capital for expansion or buyouts. The invested companies are likely to have significant assets and therefore a higher debt capacity. By contrast, in our sample investments are largely made by venture capitalist, who invest in early-stage, high-technology companies with relatively few assets. Moreover, note that in the sample of LS companies face severely underdeveloped banking

\footnotetext{
${ }^{1}$ Both LS and KMS contain one table where they add a dummy for whether the investor is from a common or civil law country. In both papers this simple dummy variable turns out to be statistically insignificant, and both papers then refrain from further investigating investor legal system effects.
} 
system, where the provision of standard bank loans cannot be taken for granted. Their equity investors may have to fill an additional market gap that is not present in our sample.

Similar to KMS, we also find that company legal system effects become insignificant once we control for enough investor characteristics. One subtle difference is that in our setting we need to use investor country fixed effect to render company legal system effects insignificant, whereas KMS only use measures of investor sophistication. In our setting investor sophistication, as measured by US or international investing experience, turns out to be relatively less important. However, we find that another measure of investor sophistication matters, namely the distinction between independent and captive venture capitalists, which is not pursued by LS or KMS. This finding also contributes to the literature on strategic investors (Gompers and Lerner (2000), and Hellmann, Lindsey and Puri (2005)).

\section{Theory}

The main objective of the theory is to motivate the empirical analysis and provide a conceptual framework for understanding the main empirical results. Therefore, we deliberately use a set-up that is as simple as possible. The model is a simplified version of the doublemoral hazard model which has become the workhorse of the theoretical venture capital literature (Casamatta (2003), Cestone (2004), Hellmann (1998, 2004), Inderst and Müller (2003), Repullo and Suarez (2004), Schmidt (2003)). The main novelty of the theory is to introduce the quality of the legal system into the double moral hazard model.

\subsection{Assumptions}

Consider an entrepreneur who requires an investment amount $k_{V}$ to start a company. The entrepreneur is wealth constrained and her opportunity cost of doing the venture is given by $k_{E}$. With probability $(1-p)$ the company is a failure, and it is unable to generate any cash flows. Still, the company will have some assets, that have a value $a$. For simplicity we assume that assets cannot be stolen. ${ }^{2}$ With probability $p$, the company is a success, generating additional cash flows $\pi$. (@@@ THOMAS, YOU HAD THE FOLLOWING, THAT WAS CLEARLY A HALF-BAKED REVISION, I WOULD JUST DROP THE WHOLE OF IT: The problem is that some of them may be their verifiability depends on the legal system). We assume that investors' claims on $\pi$ are legally enforceable with probability $\lambda$, so that $\lambda$ measures the quality of the legal system. With probability $1-\lambda$ the entrepreneur identifies a weakness in the legal system that allows her to divert the

\footnotetext{
${ }^{2}$ This assumption simplifies the exposition. It is easy to verify that it does not affect any of the results.
} 
cash flows $\pi$ to her pockets. Stealing is risky or otherwise costly, so that the entrepreneur's expected returns from stealing are given by $(1-\phi) \pi$, where $\phi \pi$ measures the net cost of stealing.

For the double moral hazard problem, we use a tractable specification, where the probability of generating additional cash flows is given by

$$
p=p_{0}+p_{E} e+p_{V} v .
$$

Let $e$ measure the non-contractible effort of the entrepreneur, and $v$ measure the amount of non-contractible value-adding support of the venture capitalist. For simplicity we use quadratic private effort $\operatorname{costs} c_{E}=e^{2} / 2$ and $c_{V}=v^{2} / 2$. The parameters $p_{E}$ and $p_{V}$ measure the relative importance or ability of the entrepreneur and venture capitalist. Throughout we assume that $p_{0}, p_{E}$ and $p_{V}$ are sufficiently low to ensure that $p<1$.

In this simple model, the value of the company can only take two values: $a+\pi$ on the upside, and $a$ on the downside. The venture capitalist's cash flow rights are linear, so that w.l.o.g. they can be expressed as a combination of debt and equity. Let $d$ denote the face value of debt, and $s$ the venture capitalist's equity share. The venture capitalist receives $d+s(a-d)$ on the downside and $d+s(\pi+a-d)$ on the upside.

For $\phi>s$ the entrepreneur would never want to steal, since the cost of diverting funds is greater than the cost of sharing. We focus on the non-trivial case where $\phi<s$, so that the entrepreneur always prefers stealing over sharing. Define:

$$
\Lambda=\lambda+(1-\lambda)(1-\phi)
$$

so that $\Lambda$ represents the fraction of total returns that are not lost due to appropriation by the entrepreneur. Let $u_{E}, u_{V}$ denote the utilities of the entrepreneur and venture capitalist, and $u$ the joint utility, then:

$$
\begin{aligned}
& u_{E}=(1-s)(a-d)+p \pi(\Lambda-\lambda s)-c_{E} \\
& u_{V}=d+s(a-d)+p \pi \lambda s-c_{V} \\
& u=a+p \pi \Lambda-c_{E}-c_{V}
\end{aligned}
$$

For simplicity, we assume that the venture capitalist has all the bargaining power, but relax this assumption in Section 3.4. The optimal contract maximizes $u_{V}$ by choice of $d$ and $s$, subject to $u_{V} \geq k_{V}, u_{E} \geq k_{E}$ (where $k_{V}$ is the venture capitalist's opportunity cost of the investment) and subject the two incentive compatibility constraints derived in section 3.2 . 
Three remarks on the model assumptions are of order at this point.

(@@ NOTE: THIS PARA INCLUDES LAURA'S EDITING) First, note that $\lambda$ represents legal system characteristics of both the entrepreneur and the venture capitalist. From a legal point of view, both company and investor jurisdictions matter, as both influence contracting. The variable $\lambda$ does not try to decompose the two legal system effects, since a priori we cannot tell which jurisdiction is more relevant. We leave that challenge to the empirical analysis.

Second, the parameter $p_{V}$ measures the value-adding competencies of venture capitalists. At the time of investment, these can be taken as exogenous. However, venture capital firms can also make decisions about how much they want to develop value-adding competencies. We can therefore think of $p_{V}$ as being set at some prior date, before the venture firm engages in deals.

Third, we noted above that the optimal contract can always be expressed in terms of debt and equity. This does not mean that investors are restricted to use those specific securities. Indeed, as we will discuss in the empirical analysis, venture capitalists often use convertible preferred equity. For simplicity's sake, the theoretical model does not try to distinguish between these alternative securities (see Hellmann (2006) for a detailed analysis). Instead, the model focuses on the more general trade-off between upside incentives and downside protection, which can be implemented either with a combination of debt and equity or with convertible preferred securities. ${ }^{3}$

\subsection{Optimal contracts}

To focus on non-trivial cases we assume that it is always possible to satisfy the two participation constraint. We obtain the two incentive constraints from the first-order conditions of maximizing $u_{V}$ w.r.t. $v$, and $u_{E}$ w.r.t. $e$ :

$$
e=p_{E} \pi(\Lambda-\lambda s) \text { and } v=p_{V} \pi \lambda s
$$

Increasing $s$ increases $v$ and decreases $e$, so that equity affects incentives. Interestingly, $v$ and $e$ are independent of $d$. This means that debt only transfers utility between the entrepreneur and the venture capitalist. Put differently, in this simple model, downside protection gives the venture capitalist additional cash flow rights without affecting the balance of incentives. Hellmann (2006) shows that even in a much more general setting, downside protection plays a similar role.

\footnotetext{
${ }^{3}$ To see this more formally, note that we can map convertible preferred equity into the model as follows. Let $\widetilde{d}$ denote the face (or preferred) value before conversion, and $\widetilde{s}$ the percentage equity stake after conversion. We then have $\widetilde{d}=d+s(a-d)$ and $\widetilde{s}(a+\pi)=d+s(\pi+a-d) \Leftrightarrow \widetilde{s}=s+\frac{(1-s) d}{a+\pi}$.
} 
The optimal choices of $d$ and $s$ depend on whether or not the entrepreneur's wealth constraint is binding or not. Figure 1 shows the utility frontier for the entrepreneur and venture capitalist. Its shape is standard for the double moral hazard model with wealth constraints. If the entrepreneur receives a relatively high utility $u_{E}$ (which is necessary for high values of $k_{E}$ ), then the utility frontier consists of a 45-degrees line. The entrepreneur's wealth constraint is not binding, and the two parties can implement a jointly optimal contract that we denote by $s^{*}$ and $d^{*}$ (derived below). Since debt constitutes transferable utility, the venture capitalist can increase his utility by increasing $d$, up to $d=a$. Because the entrepreneur is wealth constrained, to further increase his utility, the venture capitalist can only increase $s$ above $s^{*}$. This reduces the entrepreneur's effort level, which is inefficient and causes the utility frontier to slope at an angle less than $-45^{\circ}$ for lower levels of $u_{E}$. For very low levels of $u_{E}$, the utility frontier may even bend backwards. In this case the venture capitalist takes excessive equity (i.e., $s>\bar{s}$ where $\bar{s}$ corresponds to the peak of the utility frontier). The entrepreneur provides very little effort, to the point that the venture capitalist is worse off himself. In equilibrium the venture capitalist will never offer a contract on the backward bending part of the utility, but instead choose $\bar{s}$ at the peak of the utility frontier.

For brevity's sake, we derive the results when the wealth constraint is not binding in the main text, and deal with that case in the Appendix. In the absence of a wealth constraint, the optimal value $s^{*}$ maximizes the joint utility $u$. The first-order condition for $s^{*}$ is given by:

$$
\pi \Lambda\left(p_{E} \frac{d e}{d s}+p_{V} \frac{d v}{d s}\right)-e \frac{d e}{d s}-v \frac{d v}{d s}=0
$$

Using (1), we can solve for $s^{*}$. After some transformations we obtain:

$$
s^{*}=\frac{\Lambda}{\lambda} \frac{p_{V}^{2}}{p_{E}^{2}+p_{V}^{2}}
$$

Clearly, $s^{*}$ is larger the larger the venture capitalist's value contribution $\left(p_{V}\right)$, and the smaller the entrepreneur's value contribution $\left(p_{E}\right)$. The following lemma considers the effect of $\lambda$ on $s^{*}$.

Lemma 1 The venture capitalist's optimal share $s^{*}$ is decreasing in $\lambda$.

The intuition for Lemma 1 is that a better legal environment redistributes rents from the entrepreneur to the venture capitalist. In a double moral hazard setting, this upsets the balance of incentives. The optimal contract addresses this by allocating a lower share of equity to the venture capitalist. It is interesting to note that Lemma 1 is empirically 
supported by LS, who find that venture capitalists hold larger equity stakes in countries with weaker legal protection.

Using (2), the equilibrium effort levels are given by:

$$
e^{*}=\frac{p_{E}^{3}}{p_{E}^{2}+p_{V}^{2}} \Lambda \pi \text { and } v^{*}=\frac{p_{V}^{3}}{p_{E}^{2}+p_{V}^{2}} \Lambda \pi
$$

With this we examine the provision of value-adding support.

Proposition 1 (Support) The optimal level of value-added support $v^{*}$ is increasing with the quality of the legal system $\lambda$, i.e., $\frac{d v^{*}}{d \lambda}>0$.

Proposition 1 yields a first testable implication, that there is a positive relationship between the quality of the legal system, and the support provided by venture capitalists.

One might wonder whether the greater support by the venture capitalist comes at the expense of a lower effort by the entrepreneur. This is not the case, since in fact $\frac{d e^{*}}{d \lambda}>0$. Because there is less diversion of cash flow, less value is wasted, and therefore it is possible to write an optimal contract that generates more effort by both the venture capitalist and the entrepreneur. Closely related to that, note that Figure 1 also shows the effect of the legal system on the utility frontier.

Next, we assess how the equilibrium level of debt $d^{*}$ depends on $\lambda$.

Proposition 2 (Downside) The optimal level of debt $d^{*}$ is increasing with the quality of the legal system $\lambda$, i.e., $\frac{d d^{*}}{d \lambda}>0$.

The proof is in the Appendix. Proposition 2 yields a second testable implication, that in a better legal system the optimal contract places more emphasis on giving the venture capitalist additional downside protection. A priori, it is not immediately clear how the quality of the legal system might affect downside protection. The intuition for proposition 2 is as follows. In a better legal system, it is harder for the entrepreneur to divert funds. Since appropriating cash flows provided incentives to the entrepreneur, it now becomes necessary to give the entrepreneur more incentives in terms of a greater equity stake. This leaves less equity for the venture capitalist, as shown in Lemma 1. The venture capitalist therefore needs to extract any additional value through stronger downside protection. Hence $d^{*}$ is an increasing function of $\lambda$.

In the Appendix we also consider the case where the wealth constraint is binding. Proposition 2 no longer applies, since a binding wealth constraint implies $d^{*}=a$, which does not depend on $\lambda$. However, both Lemma 1 and Proposition 1 continue to apply in 
the model with wealth constraints, including the case where the venture capitalist chooses the peak of the utility frontier.

\subsection{Optimal competencies}

So far, we have taken the competencies of the venture capitalist as given - in line with the extant literature. However, the legal system can also affect the venture capitalist's competencies. We can ask whether venture capitalists that operate predominantly in a better legal environment also have stronger incentives to develop value-adding competencies. This will provide a theoretical basis for empirically examining an investor "home effect."

Each venture capital firm has an exogenously given home country and develops competencies in line with its expected deal flow. This can be characterized by a probability distribution $\Omega$ over the types of entrepreneurs that it expects to invest in. Entrepreneurs may differ in terms of all model parameters. Let the vector $x$ summarizes all these deal characteristics, namely $p_{0}, p_{E}, k_{E}, k_{V}, \pi$ and $a . \Omega(\lambda, x)$ therefore describes the distribution of entrepreneurs not only in terms of $x$, but also in terms of $\lambda$. We capture the notion of an investor's home effect as follows. We assume that an investor located in a better legal system sees a deal flow with a higher proportion of deals with high $\lambda$. Formally, we equate a better domestic legal system with a first-order stochastic dominant shift of the distribution of $\lambda$, holding $x$ constant.

In our model, the value-adding competencies of the venture capitalist are represented by the support parameter $p_{V}$. We assume that the cost of developing competencies is given by a convex cost function $C_{V}\left(p_{V}\right)$. Each venture capitalist then maximizes his own utility, given by: $U_{V}=\int u_{V}(\lambda, x) d \Omega(\lambda, x)-C_{V}\left(p_{V}\right)$.

\section{Proposition 3 (Investor home effect)}

(i) The better the legal system, the more a venture capitalist develops competencies. Formally, $p_{V}$ is increasing for any first order stochastic dominant shift of $\lambda$.

(ii) For a given $\lambda$, the effect of increasing $p_{V}$ is always positive for on the amount of venture capital support $v^{*}$, although the effect on the optimal amount of debt $d^{*}$ is ambiguous.

The proof is in the Appendix. Proposition 4 consists of two parts. Part (i) shows that in better legal environments venture capital firms have greater incentives to develop value-adding competencies. Intuitively, competencies are more valuable if the legal system is good. Formally, the proof shows that the marginal benefit of developing competencies 
is increasing in $\lambda$. Part (ii) shows that, within a given legal system, venture capitalists with higher competencies provide more support. Whether or not they also ask for more downside protection, however, is ambiguous. Proposition 4 implies that in a given country there are systematic differences between domestic and foreign investors. If the foreign investors come from a better legal system, they are likely to provide more support.

\subsection{Further discussion}

Our model assumes that venture capitalists have all the bargaining power. Relaxing this does not affect Propositions 1 and 3, but it may affect Proposition 2. In the Appendix, after the proof of Proposition 2, we consider the generalized Nash bargaining solution, where the venture capitalist's bargaining power $\beta$ can take any value between zero and one. For sufficiently low equilibrium values of $d^{*}$, the positive relationship between optimal debt $\left(d^{*}\right)$ and the quality of the legal system $(\lambda)$ continues to apply for all values of $\beta$. For higher equilibrium values of $d^{*}$, we show that there exists a value $\widehat{\beta}$ (with $0<\widehat{\beta}<1$ ), such that the $d^{*}$ decreases in $\lambda$ for $\beta<\widehat{\beta}$ and increases for $\beta>\widehat{\beta}$. Thus, while our theory suggests a positive relationship between the legal system and the level of debt for a large range of parameter values, we cannot rule out a negative relationship for some parameter values.

The model uses a simple specification of returns, where there are only two states: the upside and the downside. It is easy to see that adding a third state, where the venture is a complete failure with all assets being worthless, while maybe adding some realism, would not change any of the results. More generally, Hellmann (2006) shows that the intuitive results from a model with two states carry over to a much more general specification of returns.

We model the quality of the legal system in term of the probability of stealing $\lambda$. An alternative interpretation of the model is to think of $\lambda \pi$ as the amount of cash that is verifiable, and can thus be allocated between the entrepreneur and venture capitalist. The entrepreneur is able to steal an amount $(1-\lambda) \pi$, but incurs a cost of stealing $\phi(1-$ $\lambda) \pi$. This generates identical payoffs for the venture capitalist $(\pi \lambda s)$ and entrepreneur $(\pi(\Lambda-\lambda s))$, implying that the analysis continues to apply. This alternative interpretation has the attractive feature that it makes stealing a continuous as opposed to probabilistic variable. One technical limitation, however, is that it requires linearity of contracts as an assumption. ${ }^{4}$

\footnotetext{
${ }^{4}$ In the probabilistic interpretation, there are only two outcomes, so that linear contracts are always optimal. The interpretation with continuous stealing has an additional complications that the venture capitalist could offer an artificial non-linear contract that discourages stealing. Specifically, the contract would give the entrepreneur her share allocation $(1-s)$ whenever profits are exactly $\pi$, but nothing if
} 
Finally, for simplicity we have assumed that the cost of stealing $\phi$ ) is a constant. As $\lambda$ increases, it is possible that $\phi$ increases, i.e., $d \phi / d \lambda \geq 0$. It is straightforward to show that our results continue to hold as long as $\Lambda$ is increasing in $\lambda$, i.e., $d \Lambda / d \lambda \geq 0$. This latter condition is very intuitive, as it merely says that a better legal system has fewer inefficiency losses (which is almost tautological).

\section{The Data}

In this Section we discuss the sources and nature of our data. We want to point out that the European venture capital markets is a useful setting for testing our model. European countries are broadly comparable in terms of their stages of economic development. The European venture capital market has matured considerably throughout the 1990s, growing in size and in its ability to invest in innovative companies with a potential for high-growth (Bottazzi and Da Rin (2002), Da Rin, Nicodano, and Sembenelli (2006)). And Europe has a remarkable variety of legal systems, so that we have several countries for both common and civil law countries, and countries with diverse levels of the legal indices.

\subsection{Sources of data}

Our data come from a variety of sources. Our primary source is a survey that we sent to 750 venture capital firms in the following seventeen countries: Austria, Belgium, Denmark, Finland, France, Germany, Greece, Ireland, Italy, Luxembourg, the Netherlands, Norway, Portugal, Spain, Sweden, Switzerland, and the UK. This set of countries includes all the members of the European Union in the period under study, plus Norway and Switzerland.

We contacted venture firms that satisfied three conditions: (i) in 2001 they were full members of the European Venture Capital Association (EVCA) or of a national venture capital organization, (ii) they were actively engaged in venture capital, and (iii) they were still in operations in 2002.

We deliberately excluded private equity firms that only engage in non-venture private equity deals such as mezzanine finance, management buy-outs (MBOs) or leveraged buyouts (LBOs). ${ }^{5}$ However, we did include private equity firms that invest in both venture capital and non-venture private equity deals. For these, we considered only their venture capital investments.

profits fall short of $\pi$. This non-linear contract is largely an artifact of simplifying model assumptions, and bears no resemblance to real world securities. The alternative interpretation of stealing continuous amounts remains attractive as long as one is willing to impose linearity.

${ }^{5}$ See Fenn, Liang and Prowse (2003) for a discussion of how the venture capital market is structure in two different segments, 'venture capital' and 'non-venture private equity.' 
We collected our survey data between February 2002 and November 2003. We asked venture capital firms about the investments they made between January 1998 and December 2001. The questions centered on key characteristics of the venture firm, on the involvement with portfolio companies, and on some characteristics of these companies. ${ }^{6}$ The survey asked respondents a substantial amount of detailed company-level information. We also asked information on the educational background and work experience of each venture partner.

We received 124 responses with various degrees of completeness. Of these, three venture firms had been formed in 2001 but had not yet made any investments, so we do not include them in our sample. We contacted all the venture firms that had sent us incomplete answers, and attempted to complete them whenever possible. As a further step, we augmented the survey data with information from the websites of the respondents and their portfolio companies. We also turned to commercially available databases: Amadeus, Worldscope, and VenturExpert. We use information from these databases for two purposes. First, they allow us to obtain missing information, such as the dates, stages, and amounts of venture deals. Second, we use these databases to cross-check the information obtained from respondents. Such cross-validation further enhances the reliability of our data. Overall, we obtain data on 1,652 deals made by 119 venture firms. Unlike other papers, we refrain from using data from additional rounds that an investor makes in a given company. That is, we restrict our data to the first investment made by the investor in the particular company. In the main body of the paper we focus the analysis on investments within Europe (we discuss this further in section 5.4). We thus drop also investments in non-European countries; as a result, our sample consists of a total of 1,428 deals. Moreover, our sample includes 51 investors who invest abroad, in a total of 190 foreign deals.

Can we assess the quality of our sample relative to the underlying population? Other papers in the literature avoid this question, because it is extremely difficult to gather information on the population. Unlike banks, venture capital firms are not heavily regulated and do not need to disclose information. To gather data on the population of 750 European venture capital firms, including those that did not respond to our survey, we used two sources, the commercial database VenturExpert, and the statistics published by the European Venture Capital Association (EVCA). We also made a substantial attempt to collect additional data through direct phone calls and through websites and other trade publications. With considerable effort, we were able to gather information on more than two thirds of the population.

This additional data allows us to perform several checks on how well our sample repre-

\footnotetext{
${ }^{6}$ Throughout the paper we reserve the term 'firm' for the investor (i.e., the venture capital firm) and the term 'company' to the company that receives venture financing.
} 
sents the population of European venture capital firms. First, we look at how the sample fares in spanning the underlying population. Table 1 compares the sample with the population it is drawn from. Panel A looks at the country composition. While there is some variation in response rates across countries, our data represent a comprehensive crosssection which provides a good coverage of all countries. No single country dominates the response, and no country is left out. Most notably, our sample performs well in terms of including firms from the larger venture capital markets: France, Germany, and the UK all have response rates above $13 \%$. The overall response rate of nearly $16 \%$ is larger than for comparable surveys of industrial firms, as discussed by Graham and Harvey (2001). ${ }^{7}$

Panel B looks at the structure of both sample and population in terms of organizational types. We partition the sample into independent, bank, corporate, and public venture capital firms. As we show in Bottazzi, Da Rin and Hellmann (2006), different types of venture firms behave differently, and we want to make sure that our results are not driven by the sample composition. Our sample closely reflects the distribution of types in the population.

Panel C compares the size distribution of our respondents with that of the population. We consider two possible size measures: the number of partners, and the amount under management, both measured at the end of 2001. For the sample and the population the mean and median values of partners virtually coincide. The amount under management includes all funds managed by venture capital firms, including those invested in nonventure private equity. The average firm size is larger for the population, due to the fact that several large private equity firms, that invest mainly in non-venture private equity, chose not to respond to our survey. Consistent with this, the median firm size is very similar for the sample and the population.

Another notable strength of our data is it does not rely on a few venture capital firms. Indeed, the single largest venture capital firm accounts for only $5 \%$ of the observations, and the largest five venture capital firms for only $16 \%$ of the observations.

We also examine whether our respondents report only part of their portfolio, especially if they tend to report their more successful deals. We address this concern in three ways. First, in late 2003 we checked the websites of all respondents. When we exclude 15 venture firms whose website did not list portfolio companies, we find that the portfolio companies reported to us were over $90 \%$ those listed on the websites. Since two years had elapsed from the closing of our sample, and new investments had naturally been made, we conclude that our sample covers well over $90 \%$ of all deals, suggesting that it is unlikely that our sample suffers from systematic under-reporting. Second, we compare the exit rates for our sample with the official statistics of the European Venture Capital Association (EVCA), which

\footnotetext{
${ }^{7}$ The typical response rate for such surveys is about $9 \%$.
} 
classifies as exits IPOs, mergers and acquisitions. We made an additional data collection effort and obtained exit outcomes for all of our companies, using the same classification (see Bottazzi, Da Rin and Hellmann (2006) for details). We find that $24.7 \%$ of companies in our sample had a successful exit rate over the period 1998-2005, By comparison, we count from EVCA all investments and exits over the same period and find an exit rate of $25.6 \%$. It therefore appears that our sample is not biased towards more (or less) successful companies. Third, we also consider the possibility that there may be reporting biases in our data. Respondents might choose not to answer all of our questions about their activities when their companies are not performing well. To see whether our data present any such bias, we performed some additional tests. For all of our dependent variables we correlate the exit rate with the response rate. We find that all the correlation coefficients are all below 6\%. We also estimate (unreported) Probit models to see whether the exit rate might explain reporting rates after controlling for other observable characteristics. Naturally, we can only control for those characteristics for which we have complete or near-complete reporting, namely investor characteristics and company sectors. We find that the exit rate is statistically highly insignificant. These results suggest that there is no reporting bias towards more successful companies.

\subsection{Data Variables}

In this Section we discuss how we construct our variables, whose formal definitions are given in the Variables Definition Section of the Appendix.

\subsubsection{Dependent variables}

In this paper we focus on how the legal system affects the activities of venture capitalists and their interaction with portfolio companies. Led by our theoretical model, we concentrate on two different dimensions of the venture process: value-adding support and the choice of securities. In the Appendix we provide formal definitions of these variables

The role of value-adding support (Proposition 1) has also become a central theme in venture capital research (Cassamatta (2003), Hellmann (2000, 2002), Cestone (2004)). For support we use a measure of the amount of interaction, looking at the reported frequency with which a venture capitalist is in contact with the company. This is a useful summary measure of the amount of time and effort that the venture capitalist spends on the company.

INTERACTION is a dummy variable that takes the value 1 if the venture capital firm is reported to interact with the company on a monthly or weekly basis; 0 if it interacts with on an annual or quarterly basis. We obtain the data from our survey instrument, which 
asked: How many times per year does (did) the responsible partner(s)/manager(s) personally interact with this company? (check one). Possible answers were: annually; quarterly; monthly; weekly.

Kaplan and Strömberg (2003) explain that while venture capitalists use a variety of securities, many of these perform equivalent functions. Of central importance is how the entire package of securities affects the distribution of cash flows rights, and especially to what extent the venture capitalist gets his returns on the upside as compared to the downside (Proposition 2). In an ideal scenario, we would be able to gather complete data on the allocation of cash flows rights, including all term sheets and valuations. However, since such data is extremely sensitive, and since our aim was to gather a large and representative dataset, we deliberately limited our inquiry. We collected data on the types of securities used, but not on the specific term sheets or valuations.

In our survey we asked about the entire set of securities used for each deal. This question allowed for multiple responses. Since we consider this data of interest by itself, Table 3, Panel B, tabulates, by legal system, the types of securities used in our dataset. We clearly see that the use of securities varies across legal systems.

To move beyond a mere description of the securities used, we leverage our theory. Proposition 2 predicts that the optimal amount of debt, $d^{*}$, is increasing in $\lambda$, and Lemma 1 shows that the optimal amount of equity held by the venture capitalist, $s^{*}$, is decreasing in $\lambda$. This implies that the better the legal system, the more the optimal contract places emphasis on downside protection.

While our data does not allow us to measure the exact values $d^{*}$ and $s^{*}$, we can construct proxy variables for the relative importance of downside protection. For this we use the data from Table 3 . We refer to straight debt, convertible debt and preferred equity as 'downside securities,' since they all give the venture capitalist a larger stake on the downside.

DOWNSIDE is a dummy variable that takes the value 1 if the deal includes at least one downside security, and 0 otherwise. We obtain the data from our survey instrument, which asked: Which of the following financial instruments has your firm used to finance this company? Possible answers were: common equity; straight debt; convertible debt; preferred equity; warrants. $^{8}$

In order to probe further into Proposition 2, we use information from our survey instrument to build an alternative aggregation of securities into the following three variables:

CONVERTIBLE PREFERRED is a dummy variable that takes the value 1 if the deal

\footnotetext{
${ }^{8}$ In the instructions to the survey we specified functional definitions of these different financial instruments in order to ensure consistency of responses. For example, our definition of convertible debt includes convertible preferred debt, which is a security often used in venture deals (see Kaplan and Strömberg (2003)
} 
includes convertible debt or preferred equity, and 0 otherwise.

DEBT is a dummy variable that takes the value 1 if the deal includes straight debt, and 0 otherwise.

EQUITY is a dummy variable that takes the value 1 if the deal includes common equity, and 0 otherwise.

\subsubsection{Independent variables: legal origin and legal indices}

We distinguish among three groups of independent variables.

Our first group of independent variables concerns the legal system of companies and investors. We employ three alternative measures of the quality of the legal system. Legal scholars classify national legal systems according to the legal origins of the commercial code. La Porta et. al. (1998) propose two main categories: legal systems with common law origin and legal systems with civil law origin; the former category includes Anglo-Saxon common law, while the latter includes French civil law, German civil law and Scandinavian civil law. We construct dummy variables that classify our companies according to these two categories, using civil law as the default category.

An alternative approach of classifying legal systems is to use more specific indices, which measure some aspects of the legal system. We use two standard indices: the rule of law and the procedural complexity index (see the Appendix for their formal definitions). These two indices relate directly to our concept of the 'quality' of enforcement in a legal system. In our model the parameter $1-\lambda$ measures the probability with which an entrepreneur can steal from her company without the investors detecting him. We look for empirical counterparts of this concept.

La Porta et. al. (1998) provide a detailed explanation of the rule of law index, which measures the quality of legal enforcement. Their index is based on data for the early 1990s. Since enforcement evolves over time, we use a version of the rule of law index which measures the quality of enforcement in the year 2000 and is published by the World Bank.

Our second index measure of the quality of the legal system is the index of procedural complexity, which measures the degree of legal formalism, by averaging the cost, length of time and number of steps necessary to perform two simple legal operations: recovering a bounced cheque and evicting a tenant. This index is discussed at length in Djankov et al. (2002) and is published by the World Bank's 'Doing Business' project.

In order to make our results more easily readable, we adopt a linear transformation of the procedural complexity index so that a higher value indicates less complexity. That is, we have an index of 'procedural simplicity,' so that higher index values represent better (i.e., procedurally simpler) legal systems. 


\subsubsection{Independent variables: venture firm and company variables}

Our second set of independent variables captures investor-level and deal-level effects. Building on Bottazzi, Da Rin and Hellmann (2006), we focus on the following effects:

INDEPENDENTVC, is a dummy variables that takes the value 1 if the venture capitalist defines itself as an independent venture capital firm; 0 otherwise. We obtain the data from our survey instrument, which asked: Would you define your firm as (check one): Independent venture firm, Corporate venture firm, Bank affiliated venture firm or Other (specify). ${ }^{9}$

VCSIZE is the amount under management of the venture capital firm at the end of the sample period (2001), in millions of current euros. We obtain the data by contacting directly respondent companies after receiving their main answers. For those firms for which we had not received the information directly we gathered the data from commercial databases, company websites and industry sources.

VCAGE is the age of the venture capital firm, measured in months at the end of the sample period. We obtain the data from our survey instrument, which asked: Indicate the date of creation of your firm $(\mathrm{mm} / \mathrm{yy})$. For those firms for which we had not received the information directly we gathered the data from commercial databases, company websites and industry sources.

Following KMS we consider the importance of international experience in venture investing, and build the following variables:

VC-US-EXPERIENCE is a dummy variable that takes value 1 if the venture capital firm has invested in at least one US company.

INTERNATIONALVC is the share of a venture capital firm's investments made abroad.

Building on results by Bottazzi, Da Rin and Hellmann (2006), who show that partners' experience is an important determinant of venture investors' activism, we also look at the experience of individual venture partners, and build the following variables:

PARTNER-US-EXPERIENCE is the fraction of the venture firm's partners who have prior experience as venture partners in the US.

PARTNER-BUSINESS-EXPERIENCE is the fraction of the venture firm's partners who have prior business experience in industry or consulting. We obtain the data from our survey instrument, which asked (for each partner): Indicate the professional background (multiple answers possible): finance; industry (including previous entrepreneurial experience); accounting; consulting; legal; other (specify).

\footnotetext{
${ }^{9}$ We carefully examined the three respondents which checked the 'other' category. One is a public university fund, and was classified as public; another is a family-controlled fund, and was classified as independent; the third is a fund owned by a a government company which engages in financing for small businesses, and was classified as public.
} 
Our final set of variables captures the effects of deal-level characteristics.

STAGE is an ordered variable that takes values 1 to 4 if a deal is reported as seed, startup, expansion or bridge. We obtain the data from our survey instrument, which asked: Indicate the type of your first round of financing to this company (check one). Possible answers were: Seed; Start-up; Expansion; and Bridge.

INDUSTRY is set of a dummy variables that we obtain the data from our survey instrument, which gave the following choices: Biotech and pharma; Medical products; Software and internet; Financial services; Industrial services; Electronics; Consumer services; Telecom; Food and consumer goods; Industrial products (incl. energy); Media ES Entertainment; Other (specify).

Table 2, Panel A, contains descriptive statistics for all the variables used in the analysis. The number of observations differs across regressions because of missing values for some of the variables. We discuss this further in Section 6. Table 2 Panel B, shows the means (or frequency) of our main dependent and independent variables across legal origins.

\section{Empirical Results}

\subsection{Main effects}

We are now in a position to empirically test our theoretical propositions. Our empirical base regression is as follows:

$$
Y_{i c}=\text { Legal } * \beta_{1}+X_{i}^{\prime} \beta_{i}+X_{c}^{\prime} \beta_{c}+\varepsilon_{i c}
$$

where $i$ indexes investors and $c$ indexes companies. The dependent variables $Y_{i c}$ measures for investor $i$ in company $c$ the level of INTERACTION or DOWNSIDE. We use an ordered Probit model for INTERACTION, and a simple Probit model for DOWNSIDE, $X_{i}^{\prime}$ is a vector of investor characteristics (INDEPENDENTVC, VCSIZE and VCAGE), and $X_{c}^{\prime}$ is a vector of company characteristics (STAGE and INDUSTRY). Since our data consists of multiple investments made by different venture capital firms, we cluster our standard errors by venture capital firms. This allows for the error term $\varepsilon_{i c}$ to be correlated within the deals made by a venture capital firm, and imposes a conservative standard for accepting statistically significant results. Clustering also implies the use of heteroskedasticity-robust standard errors. Finally, Legal is a legal systems measure (legal origin, rule of law index, or procedural simplicity index), and we examine these both from the company's and investor's perspective. Because of multi-collinearity we use the standard approach in the literature and refrain from estimating jointly the effects of company and investor legal systems - i.e., 
we do not employ company and investor indices, nor different types of indices, in the same regression.

Table 3 shows the correlation matrix among the main dependent and independent variables. We note that both INTERACTION and DOWNSIDE are positively correlated with all of the legal system indices, at statistically significant level. We will return to some of these correlations later.

Univariate correlations are informative, but they obviously do not control for other company and investor effects. In terms of company characteristics, we control for industry and stage. In terms of investor characteristics, we control for the age and size of the venture capital firm. Our prior research (Bottazzi, Da Rin and Hellmann (2006)) also shows that an important factor is whether a venture capital firm is organized as independent or captive. Independent venture capital firms are conceived as specialized organizations, whose sole purpose is to maximize profit. Captive venture capital firms are investment vehicles that are used by established companies, banks, or the government, to achieve both profits as well as broader strategic goals (Hellmann (2002), Hellmann, Lindsey, and Puri (2005)). We therefore also control for whether a venture capital firm is independent or not.

Table 4 reports our empirical base model. Panel A examines the effect of legal systems on the INTERACTION variable, Panel B on the DOWNSIDE variable. We find that the legal system has a strong effect on both of these outcome variables. All coefficients are positive and statistically significant, most of them at the $1 \%$ level. The estimates also appear to be economically large. For example, the probability of downside protection is $31 \%$ higher for a common law company than for a civil law company and the probability of frequent interactions is $20 \%$ higher. ${ }^{10}$ For the rule of law index, we find that, relative to a French company, a UK company's probability of downside protection by $17 \%$ higher and the probability of frequent interactions is $23 \%$ higher. The procedural index regressions produce similar magnitudes.

Whether a venture capital firm is independent or captive has a very strong effect. The coefficient for independent venture capital is positive and statistically significant at the $1 \%$ level for INTERACTION and 5\% for DOWNSIDE. Obtaining finance from an independent venture firm raises the probability of frequent interaction by $15 \%$ and of downside protection by $20 \%$. This is an interesting result by itself, confirming and extending some of the prior findings on the distinction between independent and captive venture capital. It is also interesting to note from Table 3 that independent venture capital itself is positively correlated with the legal indices. In unreported regressions we confirm that this univariate correlation continues to hold in a multi-variate regression that also controls for company

\footnotetext{
${ }^{10}$ To calculate the economic effect for the interaction variable, which is a categorical variable, we create a dummy variable that takes value 1 if interaction is 'frequent' (i.e., monthly or weekly), and zero otherwise.
} 
characteristics (stage and industry). This suggests that in addition to the direct effect of the legal system, there is a complementary indirect effect: in better legal systems, venture capitalists are organized more often as independent entities, which then have more interaction with their portfolio companies and ask for more downside protection. Note also that we can think of the organizational choice as an investment in competencies as modeled in Section 3.3. In better legal systems, it is more worthwhile to adopt an organizational form that has a comparative advantage at interacting with entrepreneurs and providing them value-adding support.

The other variable that is statistically significant is the age of venture capital firms. We find that older firms are less interactive with their entrepreneurs, but they ask for more downside protection. The prior literature sometimes interprets firm age as a proxy for quality or even investor sophistication (see, for example, Sørensen (2006) and Gompers et al. (2005)). We caution against placing specific interpretations on age coefficients, given that age can stand for a wide variety of effects.

\subsection{Company versus investor effects}

The analysis so far establishes the importance of the legal system. However, it does not yet allow us to say whether the company's or the investor's legal system matters more. Conceptually it is not clear which of those two effects should dominate. From a legal point of view both company and investor jurisdiction matter. While the company's country of incorporation is obviously important, investors can still use their own legal jurisdiction to protect some aspects of their investments. Indeed, legal experts point out that in practice it is often difficult to clearly delineate jurisdictional responsibilities, and that both investor and company jurisdictions influence contracts. @@@ reference!@@. From an economic point of view, one may add that contractual (as well as non-contractual) practices ought to be influenced by company characteristics, but that investor experience, capabilities and expectations should also matter. Since there is no clear conceptual answer, the question naturally lends itself to empirical examination.

We propose a new method of disentangling company and investor effects that is based on comparing two sets of fixed effect regressions. The first set of regressions uses fixed effects for the investor's country. This provides a powerful way for controlling for all aspects that relate to the investor's country, including its legal system. Controlling for this, we examine whether the company's legal system still retains its statistical significance. If we find that it remains significant, then we have strong evidence that it matters. If it becomes insignificant, however, we can argue that the company's legal system is actually irrelevant, once investor country characteristics are accounted for. 
This first set of regressions probes into the effects of the company's legal system but does not speak to the importance of the investor's legal system. For this, we use a second set of regressions, which simply reverse roles. That is, we use a complete set of company country fixed effects and then examine whether the effects of the investor's legal system retain any statistical significance. This second set of regressions does not yield insights into the importance of company's legal systems, but provides us with a powerful test for the importance of the investor's legal system effects. Combining the insights from these two sets of regressions thus provides a comprehensive assessment of the relative importance of the legal system of companies and investors.

Table 5 shows the results of this approach. As before, Panel A reports regressions for INTERACTION and Panel B for DOWNSIDE. The first three columns report the results for the model with investor country fixed effect. They inform us about the importance of the company's legal system. The last three columns report the results for the model with company country fixed effects, showing the importance of the investor's legal system. The results are strikingly clear. After controlling for investor-country fixed effects, the estimates for the company's legal system become all statistically insignificant. In contrast, the estimates for the investor's legal system retain their size and statistical significance. This patterns is true both for the INTERACTION and DOWNSIDE regressions. ${ }^{11} \mathrm{We}$ believe this is a new and important result. It shows that in order to fully understand the effect of legal systems, looking at the company's legal system is not enough, and possibly misleading. Our results show the greater importance of investor rather than company effects of the legal system. ${ }^{12}$

The remainder of this Section looks at a number of extensions. Because of the clear message of Table 5, from now on we omit the discussion of companies' legal systems variables and focus our attention on the effects of investors' legal systems.

\subsection{Simple versus sophisticated securities}

The analysis so far looks at a summary measure of downside protection. In Section 3 we already noted that there exist alternative ways of implementing downside protection. One way is to use simple debt. A more sophisticated method involves the use of convertible

\footnotetext{
11@@@@@@ The only exception is in column 4 of Panel A, where the significance level dips to @\%.

${ }^{12}$ Instead of using fixed effects for the countries of the companies or investors, one might also wonder about using fixed effect for the companies or investors directly. In our data we only observe a single investor for almost all of our companies, which precludes the use of company fixed effects. However, we have multiple company observations for almost all of our investors, so that we can use investor fixed effect. The results of this approach are hardly surprising. Table 7 already shows that using investor-country fixed effect renders all the legal systems variables insignificant. Going to a finer-grained specification with individual investor fixed effects does not alter this conclusion.
} 
securities. Our parsimonious theory does not try to distinguish between those two types, but a prior literature explains the advantages of such convertible securities (see, in particular, Hellmann (2006) and Schmidt (2003)). Moreover, the empirical work of LS and KMS focuses on the distinction between simple versus sophisticated contractual features. A natural question in our context is thus whether legal systems have a differential impact on the use of simple versus sophisticated securities.

Our data on securities is not as detailed as that of LS and KMS, but it still allows us to distinguish between two types of downside protection: simple debt versus more sophisticated securities such as convertible debt or preferred equity. Moreover, we can also look at which securities are used to allow investors reaping substantial benefits on the upside, distinguishing between the use of straight equity and of more sophisticated securities such as preferred equity or convertible debt. For this part of the analysis we use the variables CONVERTIBLE PREFERRED, DEBT and EQUITY, whose construction is described in Section 4.

Using these variables, we separately estimate the base model of Table 4 and the company country fixed effect model of Table 5. The results are reported in Panels A, B, and $\mathrm{C}$ of Table 6 . The effects of the investor's legal system continue to be positive in all the regressions for CONVERTIBLE PREFERRED (Panel A) and for DEBT (Panel B). The significance levels are somewhat lower, with some coefficients being only marginally insignificant.

A closer look reveals an interesting pattern. To investigate whether a simple security like debt may be a substitute of more sophisticated securities like convertible debt and preferred equity for implementing downside protection, we estimate an additional regression model not reported here. We re-run the regressions of Panel of Panel A of Table 6 comparing deals with convertible preferred only against deals that also use debt. We find that all legal variables are statistically insignificant, consistent with the notion that debt and convertible preferred securities might be substitutes for implementing downside protection. $^{13}$

Panel $\mathrm{C}$ extends the analysis to upside gains, looking at the use of simple equity. Here, all the legal measures have a negative and significant coefficient: in better legal systems investors switch from simple equity to more sophisticated convertible preferred securities, consistent with the prior results of KMS and LS. In a similar way as for debt, we re-run the regressions of Panel $\mathrm{C}$ comparing deals with convertible preferred only against deals that also use equity. We find that all legal variables have a statistically significant negative

\footnotetext{
${ }^{13}$ We also estimate the regressions from Panel A excluding all the deals that use debt. We find that all legal measures have a positive, statistically significant effect. This suggests that if we take out debt, which as a substitute acts as a confounding factor, then we re-establish a clear relationship between legal systems and downside protection via more sophisticated securities.
} 
effect. While a simple security like debt is a good substitute for sophisticated securities for securing downside protection, the role of the legal system makes sophisticated securities more appealing than simple equity for realizing upside gains.

Overall, the results of Table 6 suggests that the main effect of a better legal system is the increased use of downside protection. To achieve this downside protection, simple debt and more sophisticated convertible securities appear to be close substitutes. The situation is different on the upside, however, as investors in better legal systems make greater use of convertible securities rather than simple equity.

\subsection{Within civil countries effects}

The literature on legal systems is often focused on the distinction between common and civil law countries. This is clearly an important distinction, but it is interesting to note than even among civil law countries, there might be considerable variation in the quality of the legal system (Djankov et. al. (2002)). @@@ a better reference? @@

Our data allow us to extend our analysis and look at the differences among civil law countries (see La Porta et. al. (1998)). There are three groups of civil law legal systems: the French, the German and the Scandinavian system. To examine such differences, we consider only the subsample of companies in civil law countries that receive financing from civil law venture capital firms. We use the rule of law and procedural complexity indices to measure the quality of the investor's legal system.

Table 7 reports the results of our regressions, which include investor legal system effects, with and without company country fixed effects. The measures of legal system quality remain statistically significant for the INTERACTION variable, suggesting that for noncontractible actions, the legal system continue to matter even with the subset of civil law countries. In the DOWNSIDE regressions we find that the legal system coefficients remain positive, but are now statistically insignificant. This suggests that the distinction between common and civil law countries is particularly important for the choice of securities, while differences within civil law legal systems do not matter much.

However, when we re-run the (unreported) regression models where we compare the use of simple versus sophisticated securities, we find that the legal system matters also within civil law countries. In particular, we find exactly the same pattern as before, whereby debt is a close substitute of convertible debt and preferred equity on the downside, while a better legal system encourages the use of these sophisticated securities over simple equity to reap upside benefits. 


\subsection{Additional investor effects}

Our analysis emphasizes the importance of investors' legal system. As with any empirical analysis, there is a concern about unobserved factors. In this section we examine whether legal system effects cannot be explained by other investor characteristics. In the next Section we also discuss the robustness of our results using additional company characteristics.

Of particular relevance for us is the question of whether we have properly accounted for other investor characteristics, especially relating to their experience with investing across different countries. KMS, for example, argue that investment styles are strongly influenced by whether investors have previous invested in the US.

We therefore consider a number of additional investor characteristics. First we look at investors' prior investment experience, and report the results in Table $8 .{ }^{14}$ Following KMS, we measure whether a venture capital firm has made any US investments. When we re-run the investor legal system regressions of Table 5, we find that adding this variable does not affect the significance of any of our legal system coefficients.

We then consider not just a venture firm's US investment experience, but whether it has any experience with investing outside of their own countries more generally. Since our country fixed effect identification strategy relies on foreign investments, we want to control for the possibility that internationally-oriented venture capitalists may have different investment styles than domestically-oriented venture capitalists. When we separate out the effect of internationally-oriented venture firms we find that all but one of the legal system coefficients remain positive and statistically significant. ${ }^{15}$ The direct effect of the internationally-oriented investor variable itself is statistically significant on the use of DOWNSIDE protection, but it has a positive coefficient that is not statistically for the INTERACTION regressions. This evidence that internationally-oriented investors are interactive is interesting in its own sake; however, it does not alter the main conclusion about the importance of investor legal systems.

Second, our data allow us to go beyond investment experience. Since we have data on individual partners, we may ask whether the professional experience of individual venture partners matters, and report the results in Table 9. Specifically, we can look precisely at US venture capital experience, not just any other US professional experience, and we examine what proportion of partners in the firms has some prior venture capital experience in the US. Again, when we re-run our regressions with partners' venture experience in the US, we find that all of the legal system coefficients remain positive and statistically significant.

\footnotetext{
${ }^{14}$ For brevity's sake, in Tables 9 and 10 we only report estimates of regressions models which include company country fixed effects. Tables without fixed effects are available upon request.

${ }^{15}$ The exception is the fixed effect regression of INTERACTION, where the coefficient of COMMONVC remains positive but becomes statistically insignificant.
} 
The direct effect of partner-level US experience is positive and highly significant in both INTERACTION and DOWNSIDE regressions. This is consistent with KMS findings of strong US experience effect.

As a final robustness check we use the insights from Bottazzi, Da Rin and Hellmann (2006), who find that an important attribute of venture capital firms is the proportion of partners that have prior direct business experience from working as managers in industry or consulting. When we include this variable in our regressions, we find that all of the legal system coefficients remain positive and statistically significant. Moreover, the direct effect of prior industry experience is not statistically significant. @@@ Do we want to mention/report/use this? If not: condense T. 8 and 9 and delete the weic row in table 2 (both panels)@@@

We conclude that even after subjecting them to a series of additional controls, the investor legal system variables remain statistically significant. This increases our confidence in the main result of the importance of investors' legal systems.

\section{Further Discussion}

In this paper we develop a simple theory for how legal systems affect venture capital activities. When we take the model to the data, we find considerable empirical support. The model thus provides a simple and intuitive explanation for the empirical findings. Naturally, one may still wonder whether there are complementary or alternative explanations for our empirical results.

One important question is whether the legal system matters because it forbids investors to take certain actions (or write certain contracts), or because it influences, possibly in more subtle and indirect ways, what investors prefer to do - along the lines of our model. We can address this question in our context by asking whether certain investor actions, such as providing value-adding support or asking for downside protection, are actually precluded by the legal system. The first five rows of Panel B of Table 2 tabulate our dependent variables across the four legal systems. While there are clear differences in the relative frequency of these activities, there are no cells with $0 \%$ or $100 \%$. This shows that none of the legal systems preclude venture capitalists from doing these activities - a result also corroborated by LS. We can therefore reject one important alternative interpretation of our results - that the legal systems matters because it simply doesn't allow investors to take certain actions.

Our analysis focus on three main measures of the quality of the legal system-legal origin, the rule of law, and procedural complexity. Other indices have been used in the literature. One such index that is worth mentioning is the 'self-dealing' index recently col- 
lected by Djankov et. al. (2005). At first glance, this index seems relevant to our analysis, since it tries to measure how easy it is for insiders to steal cash flows. However, in our context the index also has two drawbacks. First, it has been explicitly built for publicly-listed companies, whereas our analysis deals exclusively with privately-held companies. Second, the discriminatory power of the index stems mostly from the difference between common and civil law countries; for the civil law countries within our sample the index shows very little variation. Still, if we repeat our analysis using the self-dealing index, we find that our results continue to hold. @@@ CHECK OUT THE ISSUE OF MULTICOLLINEARITY - WHAT FOLLOWS IS CORRECT IN MODELS WITH NO COUNTRY FIXED EFFECTS, OTHERWISE THE INDEX IS DROPPED (AS IN THE CASE OF FULL DATASET AS WELL). The only exception occurs when we restrict the analysis to the subsample of civil law countries, where we no longer find the predicted relationships. We attribute this to the relative lack of variation in the self-dealing index for those civil law countries.

We have used a rule of law index developed by the World Bank that is widely used in the economics literature. Still, we want to check that our results do not depend on the nature of this particular index. To this purpose, we reran our regressions using an update version of the rule of law index adopted by LaPorta et. al. (1998), which is published in the International Country Risk Guide produced by the Political Risk Services Group. We obtain qualitatively very similar results.

As with any empirical analysis, there is always a question about whether we have controlled for enough other effects. With hand-collected data, there is an additional tradeoff that adding variables comes at a cost of loosing observations. Our base specification focuses on a few important investor and company characteristics. We did several additional checks to see whether other variables affect our results.

Our base model controls for the stage of the deal and the sector the company operates in. Instead of using stage, we use the closely related (and correlated) measure of company age, and obtain analogous results.

One concern might be that our sample period includes the "dotcom" period. Although still over-hyped, the dotcom wave was much smaller in Europe than in the US. Nonetheless we ask whether time periods affect our results. Adding a set of year dummies does not affect our results. It might also be argued that the dotcom period involved software deals that do not fit the traditional notion of a high-tech deal. When we drop all deals in the Internet and software industry we lose $30 \%$ of the observations but our results are virtually unchanged. A further concern is that our results are driven by differences across countries in terms of stage of development. Though our sample consists of rather homogeneous countries in this respect, we include in our regressions the per-capita GDP level of the venture capital 
firm' country; we repeat this exercise using the GDP of the portfolio company's country. None of our results is affected.

Another deal-related concern is that venture capitalists may assume different roles, depending on syndicate structures. Specifically, one might worry that lower levels of involvement in foreign deals are due to the investor not assuming the lead investor role. For the deals where we have the data, we include two additional controls, one for whether a deal is syndicated, and one for whether the investor is the lead syndicator. Again we find that this does not affect our results.

Kaplan and Strömberg (2003) note that the size of an investor's stake affects his incentive to be involved with the company. While we do not have data on equity stakes, we do have some data on the amount of money invested. First, we consider the total amount of money that a venture capitalist invests in the deal. Second, we consider what percentage of the total money raised in the round is provided by our investor. Both variables are likely to be correlated with the equity stake, and their inclusion does not affect our results.

We also did some robustness checks on our dependent variables. In the construction of our downside measure we have used the information on the entire set of securities used to finance a deal. In our survey we also asked which security was the most important in the deal, i.e., we asked what the main security used was. We make use of this additional information and modify our downside measure to include only the main security used. We use this 'exclusive' measure in our regression and find no change in the results.

\section{Conclusion}

In this paper we develop a theory of how the legal system affects optimal contracts, investor involvement, and their incentives to invest in value-adding competencies. Testing the theory on a hand-collected dataset of European venture capital deals, we confirm the model predictions. The evidence shows how the legal system affects not only the contractual, but also the non-contractual aspects of the financing relationship. We show that more than the company's legal system, it is the investor's legal system that matters. Moreover, the effect of the legal system operates not only directly through individual contracts and actions, but also more broadly by affecting the way financial intermediaries develop their own skills and capabilities.

These results show that the law and finance literature can gain new insights by adopting a wider perspective. Most of the existing empirical studies focus on understanding how the law determines contractual choices. We hope that our examination of the noncontractual aspects provides a stimulus for further work on how legal systems affects financial intermediation more broadly. 
Our evidence on the importance of legal systems for the structure of venture capital relationships also has important policy implications. The US has been widely touted as the leading example of a modern venture capital industry. As policy makers from around the world have strived to emulate the US model, they have frequently encountered numerous problems. Indeed, in the European context, there has been a lively debate about the feasibility and desirability of imitating the US venture capital model. Our theoretical and empirical analysis clarifies the limits of this imitation process. Many countries may want to foster US-style venture capital, but they rarely have in place a comparable legal system. We provide evidence that investors endogenously choose different investment styles. In the absence of reforms that strengthen the legal system, blind imitation of US venture capital practices is therefore unlikely to succeed. 


\section{Appendix}

\section{Proof of Proposition 1}

For the case where the wealth constraint is not binding, we simply take the derivative of $v^{*}$ w.r.t. $\lambda$ and find $\frac{d v^{*}}{d \lambda}=\frac{p_{V}^{3} \phi \pi}{p_{E}^{2}+p_{V}^{2}}$. The wealth constraint becomes binding whenever $k_{E}<u_{E}\left(s^{*}, d=a\right)$. For such values of $k_{E}$, the venture capitalist always sets $d=a$, and then maximizes $u_{V}=a+p \pi \lambda s-c_{V}$, subject to $u_{E}=p \pi(\Lambda-\lambda s)-c_{E} \geq k_{E}$ and subject to the first order conditions $e^{*}=p_{E} \pi(\Lambda-\lambda s)$ and $v^{*}=p_{V} \pi \lambda s$. We use the following change of variable $S=\lambda s$. We have $e^{*}=p_{E} \pi(\Lambda-S) \cdot v^{*}=p_{V} \pi S$ and $p=p_{0}+p_{E}^{2} \pi(\Lambda-S)+p_{V}^{2} \pi S$, so that after further transformations we obtain

$$
\begin{gathered}
u_{V}=a+p_{0} \pi S+p_{E}^{2} \pi^{2} S(\Lambda-S)+\frac{p_{V}^{2} \pi^{2} S^{2}}{2} \\
u_{E}=p_{0} \pi(\Lambda-S)+p_{V}^{2} \pi^{2} S(\Lambda-S)+p_{E}^{2} \pi^{2} \frac{(\Lambda-S)^{2}}{2}
\end{gathered}
$$

We note that $\frac{d u_{V}}{d S}=p_{0} \pi+p_{E}^{2} \pi^{2} \Lambda-\left(2 p_{E}^{2}-p_{V}^{2}\right) \pi^{2} S$. If $2 p_{E}^{2} \leq p_{V}^{2}$, then $\frac{d u_{V}}{d S} \geq 0$ for all values of $S$. In that case, the utility frontier is never backward bending. If $2 p_{E}^{2}>p_{V}^{2}$, then we obtain the maximal level of equity, denoted by $\bar{S}$, from $\frac{d u_{V}}{d S}(\bar{S})=0 \Leftrightarrow \bar{S}=\frac{p_{0}+p_{E}^{2} \pi \Lambda}{2 p_{E}^{2} \pi-p_{V}^{2} \pi}$. Thus $\bar{s} \equiv \frac{1}{\lambda} \frac{p_{0}+p_{E}^{2} \pi \Lambda}{2 p_{E}^{2} \pi-p_{V}^{2} \pi}$. If $\bar{s}>1 \Leftrightarrow \bar{S}>\lambda$, then $\frac{d u_{V}}{d S} \geq 0$ for all relevant values of $S$. In that case, the utility frontier is also never backward bending. For $\bar{s}<1 \Leftrightarrow \bar{S}<\lambda$, the venture capitalist never chooses $S>\bar{S}$, since that puts him on the backward bending part of the utility frontier. For $k_{E}<u_{E}(\bar{S})$, the venture capitalist thus always chooses $s=\bar{s}$. This characterizes the utility frontier.

Consider now the case with a binding wealth constraint, so that $S>\Lambda \frac{p_{V}^{2}}{p_{E}^{2}+p_{V}^{2}}$ but $S<\bar{S}$. The optimal choice of $S$, denoted for simplicity by $S^{*}$, satisfies $u_{E}\left(S^{*}\right)=k_{E}$. It is easy to verify that $u_{E}\left(S^{*}\right)$ is decreasing in $S^{*}$, and increasing in $\Lambda$ and thus $\lambda$. Totally differentiating $u_{E}=0$ we obtain $\frac{d u_{E}}{d S^{*}} d S^{*}+\frac{d u_{E}}{d \lambda} d \lambda=0 \Leftrightarrow \frac{d S^{*}}{d \lambda}=-\frac{d u_{E}}{d \lambda} / \frac{d u_{E}}{d S^{*}}>0$. From $v^{*}=p_{V} \pi S^{*}$ it follows that $\frac{d v^{*}}{d \lambda}>0$, which confirms Proposition 1. Finally, consider the case where $k_{E}<u_{E}(\bar{S})$. In this case, the venture capitalist always chooses the peak of the utility frontier. Using $v^{*}=p_{V} \pi \bar{S}$ we immediately note that $\frac{d v^{*}}{d \lambda}=\frac{p_{V} p_{E}^{2} \pi \phi}{2 p_{E}^{2}-p_{V}^{2}}>0$, which again confirms Proposition 1.

Note also that Lemma 1 continues to apply when the wealth constraint is binding. To see this, we note that $\frac{d u_{E}}{d \lambda} \sim \frac{d u_{E}}{d(\Lambda-S)}<0$ since $\frac{d(\Lambda-S)}{d \lambda}=\phi-s<0$. Clearly, $\frac{d u_{E}}{d s}<0$. 
Thus $\frac{d s^{*}}{d \lambda}-\frac{d u_{E}}{d \lambda} / \frac{d u_{E}}{d s^{*}}<0$. Finally, note that $\frac{d \bar{S}}{d \Lambda}>0$, but $\frac{d \bar{s}}{d \lambda}=\frac{1}{2 p_{E}^{2} \pi-p_{V}^{2} \pi} \frac{d}{d \lambda}\left(\frac{p_{0}}{\lambda}+\right.$ $\left.p_{E}^{2} \pi \frac{\Lambda}{\lambda}\right)<0$.

\section{Proof of Proposition 2}

We note that $d^{*}$ is determined by $u_{E}\left(d^{*}\right)=(1-s)\left(a-d^{*}\right)+p \pi(\Lambda-\lambda s)-c_{E}-k_{E}=0$. Totally differentiating w.r.t. $\lambda$ we obtain $\frac{d u_{E}}{d \lambda}+\frac{d u_{E}}{d d^{*}} \frac{d d^{*}}{d \lambda}=0 \Leftrightarrow \frac{d d^{*}}{d \lambda}=\frac{1}{1-s} \frac{d u_{E}}{d \lambda}$. We have $\frac{d u_{E}}{d \lambda}=\frac{\partial u_{E}}{\partial \lambda}+\frac{\partial u_{E}}{\partial s^{*}} \frac{\partial s^{*}}{\partial \lambda}+\frac{\partial u_{E}}{\partial e^{*}} \frac{\partial e^{*}}{\partial \lambda}+\frac{\partial u_{E}}{\partial v^{*}} \frac{\partial v^{*}}{\partial \lambda}$. Using $\frac{\partial u_{E}}{\partial \lambda}=p \pi(\phi-s), \frac{\partial u_{E}}{\partial s^{*}}=$ $-\left(a-d^{*}\right)-\lambda p \pi, \frac{d s^{*}}{d \lambda}=-\frac{p_{V}^{2}}{p_{E}^{2}+p_{V}^{2}} \frac{1-\phi}{\lambda^{2}}=-s^{*} \frac{1-\phi}{\lambda \Lambda}, \frac{\partial u_{E}}{\partial e^{*}}=0, \frac{\partial u_{E}}{\partial v^{*}}=p_{V} \pi(\Lambda-\lambda s)$ and $\frac{d v^{*}}{d \lambda}=\frac{p_{V}^{3}}{p_{E}^{2}+p_{V}^{2}} \phi \pi=p_{V} s^{*} \frac{\lambda}{\Lambda} \phi \pi$ we obtain $\frac{d u_{E}}{d \lambda}=p \pi(\phi-s)+\left(a-d^{*}\right) s^{*} \frac{1-\phi}{\lambda \Lambda}+p \pi s^{*} \frac{1-\phi}{\Lambda}$ $+p_{V}^{2}\left(\Lambda-\lambda s^{*}\right) s^{*} \frac{\lambda}{\Lambda} \phi \pi^{2}$. The second and fourth terms are always positive. The first and third term can be combined as $\frac{p \pi}{\Lambda}\left[\Lambda \phi-\Lambda s^{*}+s^{*}-\phi s^{*}\right]$. Using $1-\Lambda=(1-\lambda) \phi$ we obtain $\frac{p \pi}{\Lambda}\left[\Lambda \phi+(1-\lambda) \phi s^{*}-\phi s^{*}\right]=\frac{p \pi \phi}{\Lambda}\left[\Lambda-\lambda s^{*}\right]>0$. It follows that $\frac{d u_{E}}{d \lambda}>0$ and thus $\frac{d d^{*}}{d \lambda}>0$.

\section{Proof of Proposition 3}

Part (i): Consider first the case without a binding wealth constraint. Note that in equilibrium we have $u_{E}=k_{E}$, so that $u_{V}=u-k_{E}$, yielding $\frac{d u_{V}}{d \lambda}=\frac{d u}{d \lambda}$. We use the optimal values $e^{*}=p_{E} \pi(\Lambda-\lambda s)$ and $v^{*}=p_{V} \pi \lambda s$ to obtain $u=a+\left(p_{0}+p_{E}^{2} \pi(\Lambda-\lambda s)+p_{V}^{2} \pi \lambda s\right) \pi \Lambda$ $-\frac{\left(p_{E} \pi(\Lambda-\lambda s)\right)^{2}}{2}-\frac{\left(p_{V} \pi \lambda s\right)^{2}}{2}$. From the envelope theorem we have $\frac{d u}{d s^{*}}=0$. Thus, $\frac{d u_{V}}{d p_{V}}=$ $\frac{d u}{d p_{V}}=p_{V} \pi^{2} \lambda s(2 \Lambda-\lambda s)>0$. We have thus established that $u_{V}$ is increasing in $p_{V}$. The optimal level of $p_{V}$ is determined by $\int \frac{d u_{V}}{d p_{V}} d \Omega(\lambda, x)=C_{V}^{\prime}$. To see how this depends on the distribution of $\lambda$, we simply note that $\frac{d^{2} u_{V}}{d p_{V} d \lambda}=2 \Lambda \phi \frac{p_{V}^{2}}{p_{E}^{2}+p_{V}^{2}}\left(2-\frac{p_{V}^{2}}{p_{E}^{2}+p_{V}^{2}}\right)>0$. The marginal benefit of investing in $p_{V}$ is thus an increasing function of $\lambda$. If follows that the optimal choice of $p_{V}$ is always higher for any first order stochastic dominant shift with respect to $\lambda$.

For the case where the wealth constraint is binding, we only need to verify again that $\frac{d^{2} u_{V}}{d p_{V} d \lambda}>0$. To see this, we note that $\operatorname{sign}\left(\frac{d^{2} u_{V}}{d p_{V} d \lambda}\right)=\frac{d^{2} u_{V}}{d p_{V} d \Lambda}$. Using the expressions of $u_{V}$ and $u_{E}$ from the Proof of Proposition 1, we have $\frac{d u_{V}}{d p_{V}}=p_{V} \pi^{2} S^{2}$, so that $\operatorname{sign}\left(\frac{d^{2} u_{V}}{d p_{V} d \lambda}\right)=$ $\operatorname{sign}\left(\frac{d S}{d \Lambda}\right)$. We then use $u_{E}(S, \Lambda)=k_{E}$ to obtain $\frac{d S}{d \Lambda}=\frac{d u_{E}}{d \Lambda} /\left(-\frac{d u_{E}}{d S}\right)$. From the above 
expressions, we immediately see that $\frac{d u_{E}}{d \Lambda}>0$. Moreover, $\frac{d u_{E}}{d S}<0$ is guaranteed for all $S \geq S^{*}=\Lambda \frac{p_{V}^{2}}{p_{E}^{2}+p_{V}^{2}}$

Part (ii): We evaluate the comparative statics of $v^{*}$ and $d^{*}$ w.r.t. $p_{V}$. From $v^{*}=$ $\frac{p_{V}^{3}}{p_{E}^{2}+p_{V}^{2}} \Lambda \pi$ we note that $\frac{d v^{*}}{d p_{V}}=\frac{3 p_{V}^{2} p_{E}^{2}+5 p_{V}^{4}}{\left(p_{E}^{2}+p_{V}^{2}\right)} \Lambda \pi>0$. To see that the effect of $p_{V}$ on $d^{*}$ is ambiguous, note that $\frac{d d^{*}}{d p_{V}}=\frac{1}{1-s} \frac{d u_{E}}{d p_{V}}$ as before. We have $\frac{d u_{E}}{d p_{V}}=\frac{\partial u_{E}}{\partial p_{V}}+\frac{\partial u_{E}}{\partial s^{*}} \frac{\partial s^{*}}{\partial p_{V}}+$ $\frac{\partial u_{E}}{\partial e^{*}} \frac{\partial e^{*}}{\partial p_{V}}+\frac{\partial u_{E}}{\partial v^{*}} \frac{\partial v^{*}}{\partial p_{V}}$. Using $\frac{\partial u_{E}}{\partial p_{V}}=v^{*} \pi(\Lambda-\lambda s)>0, \frac{\partial u_{E}}{\partial s^{*}}=-\left(a-d^{*}\right)-\lambda p \pi, \frac{d s^{*}}{d p_{V}}=$ $\frac{\Lambda}{\lambda} \frac{2 p_{V} p_{E}^{2}}{\left(p_{E}^{2}+p_{V}^{2}\right)}>0, \frac{\partial u_{E}}{\partial e^{*}}=0, \frac{\partial u_{E}}{\partial v^{*}}=p_{V} \pi(\Lambda-\lambda s)$ and $\frac{d v^{*}}{d p_{V}}=\frac{3 p_{V}^{2} p_{E}^{2}+5 p_{V}^{4}}{\left(p_{E}^{2}+p_{V}^{2}\right)} \Lambda \pi>0$ we obtain $\frac{d u_{E}}{d p_{V}}=p_{V} \lambda s(\Lambda-\lambda s) \pi^{2}-\left[a-d^{*}+\lambda p \pi\right] \frac{\Lambda}{\lambda} \frac{2 p_{V} p_{E}^{2}}{\left(p_{E}^{2}+p_{V}^{2}\right)}+p_{V} \pi(\Lambda-\lambda s) \frac{3 p_{V}^{2} p_{E}^{2}+5 p_{V}^{4}}{\left(p_{E}^{2}+p_{V}^{2}\right)} \Lambda \pi$. The second term is negative. Depending on the size of $a$, it might be bigger or smaller than the sum of the first and third term. The reason for the ambiguity is that a higher value of $p_{V}$ already requires a higher value of $s$ (i.e. giving the venture capitalist more equity). Whether it also requires a higher value of debt is ambiguous.

So far the wealth constraint was not binding. For the case where the wealth constraint is binding we note that $d^{*}=a$, so the only remaining issue is to verify that $\frac{d v^{*}}{d p_{V}}>0$ continues to hold. Using $v^{*}=p_{V} \pi S^{*}$, we have $\frac{d v^{*}}{d p_{V}}=\pi S^{*}+p_{V} \pi \frac{d S^{*}}{d p_{V}}>0$ since $\frac{d S^{*}}{d p_{V}}>0$. To see this last condition, we use $u_{E}\left(S, p_{V}\right)=k_{E}$ to obtain $\frac{d S}{d p_{V}}=\frac{d u_{E}}{d p_{V}} /\left(-\frac{d u_{E}}{d S}\right)$. As before we have $\frac{d u_{E}}{d S}<0$, and it is immediate from the expressions in the proof of Proposition 1 that $\frac{d u_{E}}{d p_{V}}>0$. Hence $\frac{d S^{*}}{d p_{V}}>0$ and thus $\frac{d v^{*}}{d p_{V}}>0$.

\section{The role of bargaining power}

To see the importance of bargaining power, suppose instead that $d^{*}$ is determined by the generalized Nash bargaining solution, where $\beta$ measures the venture capitalist's bargaining power. The Nash solution maximizes $u_{V}^{\beta} u_{E}^{1-\beta}$, which yields after standard transformations the following first order condition: $\beta u_{E}-(1-\beta) u_{V}=0$. Totally differentiating this w.r.t. $\lambda$ and $d^{*}$ we obtain after further transformations $\frac{d d^{*}}{d \lambda}=\frac{1}{1-s}\left[\beta \frac{d u_{E}}{d \lambda}-(1-\beta) \frac{d u_{V}}{d \lambda}\right]$. For $\beta=1$ we regain the above framework. For $\beta<1$, we also have to take $\frac{d u_{V}}{d \lambda}$ into account. We have $\frac{d u_{V}}{d \lambda}=\frac{\partial u_{V}}{\partial \lambda_{2}}+\frac{\partial u_{V}}{\partial s^{*}} \frac{\partial s^{*}}{\partial \lambda}+\frac{\partial u_{V}}{\partial e^{*}} \frac{\partial e^{*}}{\partial \lambda}+\frac{\partial u_{V}}{\partial v^{*}} \frac{\partial v^{*}}{\partial \lambda}$. Using $\frac{\partial u_{V}}{\partial \lambda}=p \pi s, \frac{\partial u_{V}}{\partial s^{*}}=$ $\left(a-d^{*}\right)+p \pi \lambda, \frac{d s^{*}}{d \lambda}=-\frac{p_{V}^{2}}{p_{E}^{2}+p_{V}^{2}} \frac{1-\phi}{\lambda^{2}}=-s^{*} \frac{1-\phi}{\lambda \Lambda}, \frac{\partial u_{V}}{\partial e^{*}}=p_{E} \pi \lambda s, \frac{\partial e^{*}}{\partial \lambda}=\frac{p_{E}^{3}}{p_{E}^{2}+p_{V}^{2}} \phi \pi$ and 
$\frac{\partial u_{V}}{\partial v^{*}}=0$ we obtain $\frac{d u_{V}}{d \lambda}=p \pi s^{*}-\left(a-d^{*}\right) s^{*} \frac{1-\phi}{\lambda \Lambda}-p \pi s^{*} \frac{1-\phi}{\Lambda}+\lambda s^{*} \frac{p_{E}^{4}}{p_{E}^{2}+p_{V}^{2}} \phi \pi^{2}$, which we can rewrite as $\frac{d u_{V}}{d \lambda}=p \pi s^{*} \frac{\phi \lambda}{\Lambda}-\left(a-d^{*}\right) s^{*} \frac{1-\phi}{\lambda \Lambda}+\lambda s^{*} \frac{p_{E}^{4}}{p_{E}^{2}+p_{V}^{2}} \phi \pi^{2}$. The first and third term are positive, but the second term is negative. Let $A=p \frac{\phi}{1-\phi} \pi \lambda^{2}+\frac{p_{E}^{4}}{p_{E}^{2}+p_{V}^{2}} \frac{\phi}{1-\phi} \pi^{2} \lambda^{2} \Lambda$, then $\frac{d u_{V}}{d \lambda}<0$ whenever $a-d^{*}>A$, which is equivalent to $d^{*}<a-A$. If this condition holds, then we always have $\beta \frac{d u_{E}}{d \lambda}-(1-\beta) \frac{d u_{V}}{d \lambda}>0$ and thus $\frac{d d^{*}}{d \lambda}>0$ continues to apply. For $d^{*}>a-A$, however, there exists $\widehat{\beta}$, so that $\frac{d d^{*}}{d \lambda}>0$ requires $\beta>\widehat{\beta}$. For $d^{*}>a-A$ and $\beta<\widehat{\beta}$, we obtain $\frac{d d^{*}}{d \lambda}<0$.

The intuition for why $d^{*}$ is mostly increasing in $\lambda$ is as follows. Higher $\lambda$ reduces inefficient loss of value due to stealing. From Lemma 1, higher values of $\lambda$ decrease $s^{*}$. A higher value of $\lambda$ will thus always benefit the entrepreneur, i.e., $\frac{d u_{E}}{d \lambda}>0$. If $d^{*}$ is small, then $a-d^{*}$ is large, so that a higher value of $\lambda$ hurts the venture capitalist, because of the lower equity share $s^{*}$. In this case we have $\frac{d u_{V}}{d \lambda}<0$, and the sign of $\frac{d d^{*}}{d \lambda}$ is unambiguous. But for large values of $d^{*}$, the lower equity stake does not hurt the venture capitalist, so that $\frac{d u_{V}}{d \lambda}>0$. In this case, $\frac{d d^{*}}{d \lambda}$ depends on relative bargaining power. If the venture capitalist has low bargaining power $(\beta<\widehat{\beta})$, then the entrepreneur takes more of the debt, since the venture capitalist's required returns are already met by the increase in $\lambda$. But if the venture capitalist has more bargaining power $(\beta>\widehat{\beta})$, then he can extract the benefits of a better legal system through higher debt levels. 


\section{Variable definitions}

Variable definitions: (a) Dependent variables

\begin{tabular}{cl}
\hline \hline Variable & \multicolumn{1}{c}{ Description } \\
\hline INTERACTION & $\begin{array}{l}\text { ordered categorical variable that takes the values } 1 \text { to } 4 \text { if the } \\
\text { venture firm interacts with the portfolio company monthly, } \\
\text { weekly, quarterly, and annually. }\end{array}$ \\
DOWNSIDE & $\begin{array}{l}\text { dummy variable that takes the value } 1 \text { if the the finacing in- } \\
\text { struments used for the deal include straight debt, convertible } \\
\text { debt, or preferred equity; } 0 \text { otherwise. }\end{array}$ \\
DEBT & $\begin{array}{l}\text { dummy variable that takes the value } 1 \text { if the deal includes } \\
\text { straight debt; } 0 \text { otherwise. }\end{array}$ \\
CONVERTIBLE & $\begin{array}{l}\text { dummy variable that takes the value } 1 \text { if the deal includes } \\
\text { convertible debt or preferred equity; } 0 \text { otherwise. }\end{array}$ \\
ERERERED & $\begin{array}{l}\text { dummy variable that takes the value } 1 \text { if the deal includes } \\
\text { convertible debt or common equity; } 0 \text { otherwise. }\end{array}$ \\
\hline \hline
\end{tabular}


Variable definitions: (b) Independent variables: Legal systems

\begin{tabular}{|c|c|}
\hline Variable & Description \\
\hline COMPANY-COMMON & $\begin{array}{l}\text { dummy variable that takes the value } 1 \text { if the company is } \\
\text { located in a legal system of common law, from Laporta et } \\
\text { al. (1998); } 0 \text { otherwise. }\end{array}$ \\
\hline COMPANY-RULE & $\begin{array}{l}\text { measure of the quality of enforcement of legal rules in the } \\
\text { country of the portfolio company; based on an on an index } \\
\text { ranging from }-2.5 \text { to } 2.5 \text { developed by the World Bank and } \\
\text { described in Kaufmann et al. (2002). }\end{array}$ \\
\hline COMPANY-PROCEDURAL & $\begin{array}{l}\text { measure of the degree of legal formalism of the legal system } \\
\text { of the portfolio company; based on an index ranging from } 0 \\
\text { to } 100 \text {, from the World Bank Doing Business database for } \\
\text { the year } 2000 \text {. Rescaled by subtracting the original value } \\
\text { from } 100 \text {, so that a higher value corresponds to a less formal } \\
\text { (i.e., better) legal system. }\end{array}$ \\
\hline INVESTOR-COMMON & $\begin{array}{l}\text { dummy variable equal to } 1 \text { if the venture investor is located } \\
\text { in a legal system of common law and the portfolio company } \\
\text { in a legal system of civil law; } 0 \text { otherwise. }\end{array}$ \\
\hline INVESTOR-RULE & $\begin{array}{l}\text { measure of the quality of enforcement of legal rules in the } \\
\text { country of the venture investor; based on an on an index } \\
\text { ranging from }-2.5 \text { to } 2.5 \text { developed by the World Bank and } \\
\text { described in Kaufmann et al. (2002). }\end{array}$ \\
\hline INVESTOR-PROCEDURAL & $\begin{array}{l}\text { measure of the degree of legal formalism of the legal system } \\
\text { of the venture investor; based on an index ranging from } 0 \text { to } \\
\text { 100, from the World Bank Doing Business database for the } \\
\text { year } 2000 \text {. Rescaled by subtracting the original value from } \\
\text { 100, so that a higher value corresponds to a less formal (i.e., } \\
\text { better) legal system. }\end{array}$ \\
\hline
\end{tabular}




\section{Variable definitions: (c) Independent variables: investor-level and deal level controls}

\begin{tabular}{|c|c|}
\hline Variable & Description \\
\hline INDEPENDENTVC & $\begin{array}{l}\text { dummy variable that takes the value } 1 \text { if the venture capital- } \\
\text { ist defines itself as an independent venture firm; } 0 \text { otherwise. }\end{array}$ \\
\hline VC-SIZE & is the amount under management at the venture capital firm. \\
\hline $\mathrm{VC}-\mathrm{AGE}$ & $\begin{array}{l}\text { is the age of the venture capital firm, measured in months } \\
\text { at the end of the sample period. }\end{array}$ \\
\hline VC-US-EXPERIENCE & $\begin{array}{l}\text { s a dummy variable that takes value } 1 \text { if the venture capital } \\
\text { firm has invested in at leaset one US company. }\end{array}$ \\
\hline INTERNATIONALVC & $\begin{array}{l}\text { is the share of a venture capital firm's investments made } \\
\text { abroad }\end{array}$ \\
\hline $\begin{array}{l}\text { PARTNER } \\
\text { US-EXPERIENCE }\end{array}$ & $\begin{array}{l}\text { is the fraction of the venture firm's partners with prior } \\
\text { experience in US venture capital }\end{array}$ \\
\hline $\begin{array}{c}\text { PARTNER } \\
\text { BUTSINFSS_FXPFRIFNCF }\end{array}$ & is the fraction of the venture firm's partners who have prior \\
\hline STAGE & $\begin{array}{l}\text { ordered dummy variable that takes the values } 1 \text { to } 4 \text { if a deal } \\
\text { is reported as a seed, start-up, expansion, or bridge. }\end{array}$ \\
\hline INDUSTRY & $\begin{array}{l}\text { set of a mutually exclusive dummy variables that take the } \\
\text { value } 1 \text { if the company is reported to operate in one the } \\
\text { following industries Biotech and pharma; Medical products; } \\
\text { Software and internet; Financial services; Industrial services; } \\
\text { Electronics; Consumer services; Telecom; Food and con- } \\
\text { sumer goods; Industrial products (incl. energy); Media \& } \\
\text { Entertainment; Other; } 0 \text { otherwise. }\end{array}$ \\
\hline
\end{tabular}

Entertainment; Other; 0 otherwise. 


\section{References}

[1] Adams, R., 2003, 'What do board do? Evidence from Board Committee and Director Compensation Data,' Mimeo, Stockholm School of Economics

[2] Adams, Renée Daniel Ferreira (2007) 'A Theory of Friendly Boards,' Journal of Finance, 62 (1), 217-50.

[3] Bascha, Andreas and Uwe Waltz (2001) 'Convertible Securities and Optimal Exit Decisions in Venture Capital Finance,' Journal of Corporate Finance, 7 (2), 285-306.

[4] Bergman, Nittai, and Daniel Nicolaievski (2004) 'Investor Protection and the Coasian View,' forthcoming, Journal of Financial Economics.

[5] Bottazzi, Laura, and Marco Da Rin (2002) 'Venture Capital in Europe: Euro.nm and the Financing of European Innovative Firms,' Economic Policy, 17 (1), 229-69.

[6] Bottazzi, Laura, and Marco Da Rin (2004) 'Financing entrepreneurial firms in Europe: facts, issues, and research agenda,' in Christian Keuschnigg and Vesa Kanniainen (eds.) Venture Capital, Entrepreneurship, and Public Policy, Cambridge, MA, MIT Press, 3-32.

[7] Bottazzi, Laura, Marco Da Rin, and Thomas Hellmann (2006) 'Who are Active Investors? Evidence from Venture Capital,' Mimeo.

[8] Bottazzi, Laura, Marco Da Rin, and Thomas Hellmann (2007) 'The Role of Trust for Invesment: Evidence from Venture Capital,' Mimeo.

[9] Burkhart Mike, Denis Gromb, and Fausto Panunzi (1997) 'Large Shareholders, Monitoring, and the Value of the Firm,' Quarterly Journal of Economics, 112 (3), 693-728;

[10] Burkhart Mike, Fausto Panunzi and Andrei Shleifer (2003) 'Family Firms,' Journal of Finance, 58 (5), 2167-2202.

[11] Burkhart Mike, and Fausto Panunzi (2006) 'Agency Conflicts, Ownership Concentration, and Legal Shareholder Protection,' Journal of Financial Intermediation, 15 (1), 1-31.

[12] Casamatta, Catherine (2003) 'Financing and Advising: Optimal Financial Contracts with Venture Capitalists,' Journal of Finance, 58 (5), 2059-2120. 
[13] Cestone, Giacinta (2004) 'Venture Capital Meets Contract Theory: Risky Claims or Formal Control?' CEPR Discussion Paper 3462.

[14] Cumming, Douglas and Jeffrey MacIntosh (2003) 'A Cross-Country Comparison of Full and Partial Venture Capital Exits' Journal of Banking and Finance, 27 (3), 511-548.

[15] Cumming, Douglas, Daniel Schmidt, and Uwe Walz (2004) 'Legality and Venture Finance Around the World,' Mimeo.

[16] Desai, Mihir, Paul Gompers and Josh Lerner (2005) 'Institutions, Capital Constraints and Entrepreneurial Firm Dynamics: Evidence from Europe,' Harvard NOM Research Paper 03-59.

[17] Da Rin, Marco, Giovanna Nicodano, and Alessandro Sembenelli (2006), 'Public Policy and the Creation of Active Venture Capital Markets,' Journal of Public Economics, $80(8-9), 1699-723$.

[18] Demirgüç-Kunt, Asli, and Vojislav Maksimovic (1998) 'Law, Finance, and Firm Growth,' Journal of Finance, $\mathbf{5 3}$ (6), 2107-37.

[19] Dessein, Wouter (2005) 'Information and Control in Alliances and Ventures,' Journal of Finance, 60 (5), 2513-49.

[20] Djankov, Simenon, Rafael LaPorta, Florencio Lopez-de-Silanes, and Andrei Shleifer (2002) 'Courts,' Quarterly Journal of Economics, 118 (2), 453-517.

[21] Djankov, Simenon, Rafael La Porta, Florencio Lopez-de-Silanes, and Andrei Shleifer (2005) 'The Law and Economics of Self-Dealing,' NBER Working Paper 11883.

[22] Fenn, George, Nellie Liang, and Stephen Prowse (2003) ,'The Private Equity Market,'in Dennis Logue and James Seward (eds.) Handbook of Modern Finance, New York, RIA Group.

[23] Gale, Douglas, and Martin Hellwig (1985) 'Incentive-compatible debt contracts: The one-period problem,' Review of Economic Studies, 52 (4), 647-663.

[24] Gompers, Paul (1995), 'Optimal Investment, Monitoring, and the Staging of Venture Capital,' Journal of Finance, 50 (4), 1461-90.

[25] Gompers, Paul, and Josh Lerner (2000) 'Can Corporate Venture Capital Succeed?: Organizational Structure, Complementarities, and Success,' in Randall Morck (ed.) Concentrated Ownership, Chicago, University of Chicago Press, 17-50. 
[26] Gompers, Paul, Anna Kovner, Josh Lerner and David Scharfstein (2005) 'Venture Capital Investment Cycles: The Role of Experience and Specialization,' mimeo, Harvard Business School.

[27] Graham, John, and Campbell Harvey (2001) 'The Theory and Practice of Corporate Finance: Evidence from the Field,' Journal of Financial Economics, 60 (1), 187-243.

[28] Hart, Oliver (2001) 'Financial Contracting,' Journal of Economic Literature, 39 (4), $1037-1100$.

[29] Hellmann, Thomas (1998), 'The Allocation of Control Rights in Venture Capital Contracts,' Rand Journal of Economics, 29 (1), 57-76.

[30] Hellmann, Thomas (2000), 'Venture Capitalists: The Coaches of Silicon Valley,' in Chong-Moon Lee, William F. Miller, Marguerite Gong Hancock, and Henry S. Rowen (eds.) The Silicon Valley Edge: A Habitat for Innovation and Entrepreneurship, Stanford University Press, Stanford.

[31] Hellmann, Thomas (2002) 'A Theory of Strategic Venture Investing.' Journal of Financial Economics, 64 (2), 285-314.

[32] Hellmann, Thomas (2006), 'IPOs, Acquisitions and the Use of Convertible Securities in Venture Capital,' Journal of Financial Economics, 81 (3), 649-79.

[33] Hellmann, Thomas, Laura Lindsey, and Manju Puri (2004) 'Building Relationships Early: Banks in Venture Capital,' NBER Working Paper 10535.

[34] Hellmann, Thomas, and Manju Puri (2000), 'The Interaction between Product Market and Financing Strategy: The Role of Venture Capital,' Review of Financial Studies, 13 (4), 959-84.

[35] Hellmann, Thomas, and Manju Puri (2002), 'Venture Capital and the Professionalization of Start-ups: Empirical Evidence,' Journal of Finance, 57 (1), 169-97.

[36] Himmelberg, Charles, Glenn Hubbard, and Inessa Love (2002), 'Investor Protection, Ownership, and the Cost of Capital,' Mimeo, Columbia University

[37] Hochberg, Yael (2003), 'Venture Capital and Corporate Governance in the Newly Public Firm,' Mimeo, Stanford University.

[38] Holmström, Bengt, and Jean Tirole (1997) 'Financial Intermediation, Loanable Funds, and the Real Sector,' Quarterly Journal of Economics, 112 (3), 663-691. 
[39] Inderst, Roman, and Holger Müller (2004) 'The Effects of Capital Market Characteristics on the Value of Start-up Firms,' Journal of Financial Economics, 72 (2), $319-56$.

[40] Kaplan, Steven, and Per Strömberg (2003) 'Financial Contracting Theory Meets the Real World: An Empirical Analysis of Venture Capital Contracts, Review of Economic Studies, 70 (2) 281-315.

[41] Kaplan, Steven, and Per Strömberg (2004) 'Characteristics, Contracts and Actions: Evidence from Venture Capitalists Analysis,' Journal of Finance, 59 (5), 2177-210.

[42] Kaplan Steven, Frederic Martel and Per Strömberg, (2003) 'How Do Legal Differences and Learning Affect Financial Contracts?' NBER Working Paper 10097.

[43] La Porta, Rafael, Florencio Lopez-de-Silanes, Andrei Shleifer, and Robert Vishny (1997) 'Legal Determinants of External Finance,' Journal of Finance, 52 (5), 113150.

[44] La Porta, Rafael, Florencio Lopez-de-Silanes, Andrei Shleifer, and Robert Vishny (1998) 'Law and Finance,' Journal of Political Economy, 106 (6), 1133-55.

[45] La Porta, Rafael, Florencio Lopez-de-Silanes, Andrei Shleifer, and Robert Vishny (2000) ' Investors Protection and Corporate Governance', Journal of Financial Economics, 58 (1-2), 3-27.

[46] Lerner, Josh (1994) 'Venture Capitalists and the Decision to go Public,' Journal of Financial Economics, 35 (1), 293-316.

[47] Lerner, Josh (1995) 'Venture Capitalists and the Oversight of Private Firms,' Journal of Finance, 50 (1), 301-18.

[48] Lerner, Josh, and Antoinette Schoar (2004) 'Does Legal Enforcement Affect Financial Transactions? The Contractual Channel in Private Equity,' Quarterly Journal of Economics 120 (1), 223-46.

[49] Lindsey, Laura (2003) 'The Venture Capital Keiretsu Effect: An Empirical Analysis of Strategic Alliances among Portfolio Firms,' Mimeo, Stanford University.

[50] Lorsch Jay, and Elizabeth MacIver (1989) Pawns or Potentates, Harvard Business School Press, Boston, MA.

[51] Megginson, William (2004) 'Towards a Global Model of Venture Capital?' Journal of Applied Corporate Finance, 17 (1), 8-26. 
[52] Qian, Jun, and Philip Strahan (2005) 'How Law and Institutions Shape Financial Contracts: The Case of Bank Loans,' forthcoming, Journal of Finance.

[53] Reynolds Thomas and Arturo Flores, (1989) Foreign Law: Current Sources of Codes and Basic Legislation in Jurisdictions of the World, Littleton, Rothman.

[54] Repullo, Rafael, and Javier Suarez (2004) 'Venture Capital Finance: A Security Design Approach,' The Review of Finance, 8 (1), 75-108.

[55] Sahlman, William (1990) 'The Structure and Governance of Venture Capital Organizations,' Journal of Financial Economics, 27 (2), 473-52

[56] Schmidt, Klaus (2003) 'Convertible Securities and Venture Capital Finance,' Journal of Finance, 58 (3), 1139-66.

[57] Shleifer and Wolfenzon (2002) 'Investor Protection and Equity Markets,' Journal of Financial Economics, 66 (1), 3-27

[58] Sørensen, Morten (2006) 'How Smart is Smart Money: An Empirical Two-Sided Matching Model of Venture Capital,' forthcoming, Journal of Finance. 